\title{
Pigs receiving daily tailored diets using precision-feeding techniques have different threonine requirements than pigs fed in conventional phase-feeding systems
}

\author{
Aline Remus ${ }^{1,2,3}$, Luciano Hauschild ${ }^{3}$, Etienne Corrent ${ }^{4}$, Marie-Pierre Létourneau-Montminy ${ }^{2}$ and \\ Candido Pomar ${ }^{1,2,3^{*}}$
}

\begin{abstract}
Background: There is large variation in amino acids requirements among pigs, hence feeding pigs individually with daily tailored diets or in groups with a single feed may require different levels of nutrients. Thus, the response to different threonine levels $(70 \%, 85 \%, 100 \%, 115 \%$, and 130\% of the ideal threonine:lysine protein ratio of 0.65$)$ was studied in growing pigs raised in a conventional group phase-feeding (GPF) system or fed individually using individual precision-feeding (IPF) techniques. In a 21-day trial, 110 barrows ( $25 \pm 0.80 \mathrm{~kg}$ body weight) were housed in the same room and fed using electronic feeders. Five pigs per treatment were slaughtered at the end of the trial.

Results: Threonine intake increased linearly for the IPF and GPF pigs $(P<0.05)$. Lysine intake was similar across the treatments. Average daily gain, gain:feed ratio, and protein deposition were affected linearly by threonine level $(P<0.05)$ in both feeding systems. Protein deposition in the GPF pigs was maximized at $150 \mathrm{~g} / \mathrm{d}$ and a 0.65 threonine: lysine ratio, whereas protein deposition increased linearly in the IPF pigs. Plasma Met and serine levels were 11 and 7\% higher, respectively, in the IPF pigs than in the GPF pigs $(P<0.05)$. Dietary threonine increased $(P<0.05)$ threonine concentration in the longissimus dorsi in a quadratic manner in the IPF pigs, whereas there was no effect in the GPF pigs. Longissimus dorsi collagen decreased as dietary threonine increased in the IPF and GPF pigs $(P<0.10)$. Carcass muscle crude protein was $2 \%$ higher in the GPF pigs than in the IPF pigs $(P<0.05)$.
\end{abstract}

Conclusions: Individual pigs are able to modulate growth and the composition of growth according to threonine intake. The average amino acid ratio value that is currently used for GPF cannot be used for IPF.

Keywords: Amino acid body composition, Dose-response, Ideal protein profile, Lysine, Threonine

\section{Background}

Pigs are usually fed in groups with the same diet provided during each feeding phase, and the composition of the diet is adjusted to the estimated nutrient requirements of a representative animal in the group. These requirements are often estimated using factorial methods in which the average pig is taken as the reference for the population (e.g., National Research Council, 2012 [1]).

\footnotetext{
* Correspondence: candido.pomar@canada.ca

'Sherbrooke Research and Development Centre, Agriculture and Agri-Food Canada, Sherbrooke, Quebec J1M 0C8, Canada

2Département des sciences animales, Université Laval, Quebec City, Quebec G1V 0A6, Canada

Full list of author information is available at the end of the article
}

However, pigs have different requirements, and these requirements change over time [2]. Optimal responses in conventional group phase-feeding (GPF) systems are, however, obtained with levels of nutrients that satisfy the requirements of the most demanding animals in the group, because for most nutrients, underfed pigs exhibit reduced growth performance, whereas overfed ones exhibit near optimal performance [2, 3]. Indeed, most of the pigs receive more nutrients than they need to express their growth potential [2]. Feeding pigs with daily tailored diets using individual precision-feeding techniques (IPF) is proposed to alleviate the limitations of group-feeding systems [4, 5]. Individual lysine (Lys) 
requirements are estimated in IPF systems according to each pig's daily feed intake, body weight (BW), and daily gain patterns [2]. Other amino acid (AA) requirements are established according to a recognized ideal AA profile using Lys as the reference AA. It has been demonstrated that, in relation to conventional GPF systems, precision feeding can reduce Lys intake by $26 \%$, nitrogen excretion by $30 \%$, and feeding costs by $10 \%[6,7]$. The ability of the proposed method to estimate individual pig Lys requirement has been validated $[8,9]$, but no validation of the method's estimation of other AA requirements, which today are estimated using a conventional ideal AA profile, has been performed. It has been recently observed, however, that pigs fed daily tailored diets might have higher methionine (Met):Lys ratios than pigs in GPF systems do [10].

Threonine (Thr) is often the second-limiting AA in conventional commercial diets, and feeding pigs AA deficient diets limit protein deposition (PD) and affects tissue protein composition $[11,12]$. Thus, Thr deficiency might lead to the synthesis of proteins with less Thr and a reduction of the Thr concentration in the overall body muscles [13]. Because IPF significantly reduces Lys intake, we hypothesized that the ideal AA profile may differ between IPF and GPF systems and that using the current AA recommendation may limit PD and change plasma and muscle AA concentrations in precision-fed pigs. The aim of this study was to evaluate metabolic changes due to feeding pigs with increasing levels of dietary Thr $(70 \%, 85 \%, 100 \%$, $115 \%$, or $130 \%$ of the estimated ideal standardized ileal digestible [SID] Thr:Lys ratio of 0.65 [14]) on animal growth performance and on plasma and body protein AA concentrations in IPF and GPF systems.

\section{Methods}

Animals, housing, and management

Animals were cared for in accordance with a recommended code of practice [15] and the guidelines of the Canadian Council on Animal Care [16], and the animal trial was approved (Case No. 478) by the Ethical and Animal Welfare Committee of Agriculture and Agri-Food Canada's Sherbrooke Research and Development Centre (Sherbrooke, QC, Canada).

A total of 110 healthy barrow pigs of the same highperformance genotype (Fertilis $25 \times$ G-Performer 8.0; Geneticporc Inc., St-Gilbert, QC, Canada) were shipped to the swine complex at the Sherbrooke Research and Development Centre. The pigs were allocated to one of two $76-\mathrm{m}^{2}$ pens with concrete slat floors in the same mechanically ventilated room. The pigs each had an electronic chip placed in their ear to give them access to the feeders. Between their arrival and the start of the trial, the pigs were fed commercial growing diets. Water was provided with low-pressure nipple drinkers, and feed was provided individually ad libitum throughout the adaptation period (14 d) and experimental period (21 d) with 10 feeding stations (Automatic and Intelligent Precision Feeder; University of Lleida, Lleida, Spain). The temperature of the room was decreased gradually from $22{ }^{\circ} \mathrm{C}$ when the piglets arrived to $18{ }^{\circ} \mathrm{C}$ at the end of the experimental period to ensure thermoneutral conditions. The photoperiod consisted of $12 \mathrm{~h}$ of light and $12 \mathrm{~h}$ of darkness. The pigs' health status was checked daily. This check included daily observations of DFI records and monitoring for the presence of diarrhea and for other signs of health disorders. Body temperature was measured when distress conditions were observed, and pigs were treated in accordance with veterinarian recommendations when necessary.

The pigs $(25 \pm 0.80 \mathrm{~kg} \mathrm{BW})$ were assigned randomly to the treatments in two complete blocks according to a $2 \times 5$ factorial arrangement, with the main factors being (1) two feeding systems (IPF or GPF), and (2) five Thr levels $(70 \%, 85 \%, 100 \%, 115 \%$, or $130 \%$ of the estimated ideal Thr:Lys ratio of 0.65 [14]). The experimental unit was the individual pig, and each treatment included 11 replicates. Each of the two complete blocks included 55 pigs, and the blocks started the experimental period one week apart. Pigs within each block were housed in the same pen. Individual transponder codes allowed the feeders to identify individual pigs, record feed intake data and the feeds to be provided to each pig according to the assigned feeding system and Thr level. In each single-space feeder, precision Archimedes screw conveyors delivered and simultaneously blended volumetric amounts of up to four feeds stored in independent containers located in the top of the feeder [17]. The feeder identified each pig when the feed demand was made, and the feeder read the specific treatment formula for that pig, mixed the feed in accordance with the assigned treatment, and dropped the feeds into the feeder tray. A time lag between services was set in accordance with the pig's BW and feed intake. All the feeders were designed to provide meals to all the animals, regardless of the treatment. Because of this feature, all the animals could be housed in the same pen $[6,18]$ and each animal could be considered an experimental unit.

\section{Feeding programs, nutritional requirements, and diets}

Data from high-performance pigs from previous trials completed at the Sherbrooke Research and Development Centre were used as the reference population for calculating the pigs' Lys requirement to formulate the feeds (named A1, A2, B1, and B2) (Table 1). The formulation of these feeds was performed using each ingredient's SID AA content obtained by determining the product of its tabulated total AA content [1] and the SID value in the INRA-AFZ tables [19]. The four experimental feeds were formulated to contain similar net energy concentrations and AA profiles for AA other than Thr. The AA were 
Table 1 Ingredient and chemical composition (as-fed basis) of the experimental feeds (A1, A2, B1, and B2)

\begin{tabular}{|c|c|c|c|c|}
\hline Item & $\mathrm{A} 1$ & $\mathrm{~A} 2$ & B1 & B2 \\
\hline \multicolumn{5}{|l|}{ Ingredients $\mathrm{g} / \mathrm{kg}$} \\
\hline Corn & 533 & 538 & 537 & 538 \\
\hline Soybean meal (48\%) & 173 & 173 & - & - \\
\hline Wheat & 150 & 150 & 100 & 100 \\
\hline Canola meal & 47 & 47 & - & - \\
\hline Corn gluten meal + linseed meal $^{a}$ & 33 & 33 & - & - \\
\hline Corn starch & - & - & 156.3 & 156.3 \\
\hline Fat & 16 & 16 & 35 & 35 \\
\hline Oat hulls & - & - & 143 & 143 \\
\hline Limestone & 12 & 12 & 8 & 8 \\
\hline Monocalcium phosphate & 10 & 10 & 8 & 8 \\
\hline Salt & 5.50 & 5.50 & 4.80 & 4.80 \\
\hline Anti-mould & 1.00 & 1.00 & 1.00 & 1.00 \\
\hline Choline chloride (75\%) & 0.20 & 0.20 & 0.20 & 0.20 \\
\hline Lysine sulfate (70\%) & 6.70 & 6.70 & 2.80 & 2.80 \\
\hline L-threonine & 4.50 & - & 1.20 & - \\
\hline DL-methionine & 2.30 & 2.30 & 0.20 & 0.20 \\
\hline L-valine $(96.5 \%)$ & 2.10 & 2.10 & 0.20 & 0.20 \\
\hline Vitamin mineral premix ${ }^{\mathrm{b}}$ & 2.00 & 2.00 & 2.00 & 2.00 \\
\hline L-tryptophan & 1.10 & 1.10 & 0.30 & 0.30 \\
\hline L-isoleucine & 0.70 & 0.70 & 0.20 & 0.20 \\
\hline \multicolumn{5}{|l|}{ Chemical composition, $\%$} \\
\hline Dry matter & 90.85 & 91.25 & 92.99 & 92.67 \\
\hline Crude fat & 6.79 & 6.74 & 7.88 & 8.44 \\
\hline Crude protein & 19.85 & 19.88 & 7.5 & 6.88 \\
\hline Acid detergent fibre & 3.87 & 4.02 & 6.32 & 6.51 \\
\hline Neutral detergent fibre & 8.80 & 8.63 & 13.58 & 14.12 \\
\hline Total calcium & 0.72 & 0.72 & 0.50 & 0.49 \\
\hline Total phosphorus & 0.64 & 0.64 & 0.40 & 0.40 \\
\hline Digestible phosphorus $^{c}$ & 0.35 & 0.35 & 0.27 & 0.27 \\
\hline $\mathrm{SID}^{\mathrm{d}}$ isoleucine & 0.67 & 0.69 & 0.22 & 0.21 \\
\hline SID leucine & 1.34 & 1.39 & 0.64 & 0.59 \\
\hline SID lysine & 1.07 & 1.07 & 0.34 & 0.33 \\
\hline SID methionine & 0.53 & 0.53 & 0.16 & 0.14 \\
\hline SID methionine + cysteine & 0.72 & 0.72 & 0.24 & 0.20 \\
\hline SID phenylalanine & 0.75 & 0.77 & 0.28 & 0.26 \\
\hline SID serine & 0.80 & 0.80 & 0.30 & 0.26 \\
\hline SID threonine & 0.98 & 0.58 & 0.31 & 0.19 \\
\hline SID valine & 0.89 & 0.89 & 0.29 & 0.27 \\
\hline Calculated net energy, MJ/kg & 13.43 & 13.49 & 13.63 & 13.65 \\
\hline
\end{tabular}

${ }^{a}$ Mix of corn gluten meal and linseed meal (Shur-Gain Canada)

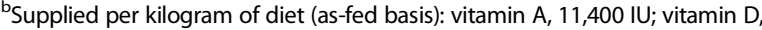
$1140 \mathrm{IU}$; vitamin E, $35 \mathrm{IU}$; vitamin K, 2 mg; vitamin $\mathrm{B}_{12}, 30 \mu \mathrm{g}$; niacin, $20 \mathrm{mg}$; pantothenic acid, $15 \mathrm{mg}$; pyridoxine, $2 \mathrm{mg}$; thiamine, $2 \mathrm{mg}$; copper, $122 \mathrm{mg}$; iodine, $0.3 \mathrm{mg}$; iron, $100 \mathrm{mg}$; manganese, $63 \mathrm{mg}$; selenium, $0.3 \mathrm{mg}$; and zinc, $152 \mathrm{mg}$

'Digestible phosphorus, standardized ileal digestible amino acids, and metabolizable energy were estimated from the analyzed total amino acid and crude energy content in feed and from values in the INRA-AFZ tables [19]

${ }^{d}$ SID, standardized ileal digestible provided $10 \%$ above the ideal AA:Lys ratios: $30 \%$ for Met [13], 60\% for Met + cysteine [13], 65\% for Thr [14], 22\% for tryptophan [20], 70\% for valine (Val) [21], 51\% for isoleucine (Iso) [22], 100\% for leucine (Leu) and 32\% for histidine (His) [22] and 42\% for arginine (Arg) [1], whereas Lys was provided $10 \%$ under the estimated requirements [2]. Feeds A1 and A2 were formulated to satisfy the requirements for minerals and AAs other than Thr of the most demanding pigs in the reference population, and feeds $B 1$ and B2 were formulated to satisfy the requirements for minerals and AAs other than Thr of the less demanding pigs in the reference population $[2,6,7]$. However, feeds $\mathrm{A} 1$ and $\mathrm{B} 1$ were formulated to provide $130 \%$ of the optimal Thr:Lys level, and feeds A2 and B2 were formulated to provide $70 \%$ of the optimal Thr:Lys level. Dietary phosphorus and calcium requirements were estimated according to the National Research Council [1]. Microbial phytase was not added, but the calcium:digestible phosphorus ratio was kept constant.

Dietary treatments for the IPF and GPF pigs were obtained by blending the four experimental feeds in the required proportions. For the IPF pigs, the required daily concentration of SID Lys was estimated with a mathematical model using individual feed intake and weekly BW information [2]. With this historical information, the empirical component of the model estimated, for each pig, the expected BW, DFI, and weight gain for the starting day on which the pig would receive the calculated feed blend. Thereafter, the mechanistic component of the model used these three estimated variables to calculate, by means of a factorial method, the optimal concentration of Lys that should be offered that day to each pig in the herd to meet its requirements. This method of estimating nutrient requirements was described previously $[2,6]$ and validated in three earlier studies [7-9]. The use of this model allowed each pig in the IPF system to receive, each day, a diet tailored to its Lys requirement. In the GPF system, Lys requirement was estimated by assuming that the population requirements were those of the $80^{\text {th }}$-percentile pig in the group at the beginning (average of $3 \mathrm{~d}$ ) of the phase [10, 23] and maintained constant for all pigs through out the feeding phase. However, SID Lys supplies were decreased by $10 \%$ to ensure that Lys was the second-limiting AA [24], whereas the other AAs except Thr were provided 10\% above the estimated levels. Threonine was provided at the assigned treatment level. The AA ratios were calculated in the same way in both feeding systems and kept constant throughout the experiment.

\section{Experimental measurements Performance}

The pigs were weighed at arrival and three times during the adaptation period to calibrate the model before the 
experimental protocol was applied. Animal performance was evaluated through average daily feed intake (ADFI) $(\mathrm{kg} / \mathrm{d})$, average daily gain (ADG) $(\mathrm{kg} / \mathrm{d})$, gain:feed ratio (G:F) $(\mathrm{kg} / \mathrm{kg})$, SID Lys intake (g/d), SID Thr intake (g/d), total body PD (g/d), PD in daily gain (\%), and total body lipid deposition (LipD) (g/d). Total body fat and lean content were measured by dual X-ray absorptiometry (DXA) on d 1 and 21 of the trial with a densitometer device (GE Lunar Prodigy Advance, Madison, WI, USA). The pigs were scanned in the prone position using the total-body scanning mode of the manufacturer-provided software (Lunar enCORE Software, version 8.10.027). Anesthesia was induced with sevoflurane (7\%) and maintained with isoflurane (5\%) during the scans.

\section{Blood sampling}

Blood samples were taken on d 21 after $10 \mathrm{~h}$ of fasting. Samples from the jugular vein were collected in Vacutainer tubes with EDTA anticoagulant for enzymatic and biochemical analyses or with sodium heparin for the AA analysis. The time between sampling and centrifugation did not exceed $1 \mathrm{~h}$, during which the samples were kept on ice. The blood samples were centrifuged for $15 \mathrm{~min}$ at $1000 \times g$ at $4{ }^{\circ} \mathrm{C}$. For AA analysis, $20 \mu \mathrm{L}$ of standard enriched AAs was added to the samples within $30 \mathrm{~min}$ after centrifugation. All plasma samples were kept at $-20^{\circ} \mathrm{C}$ during the sampling day and stored at $-80^{\circ} \mathrm{C}$ at the end of the day.

\section{Organ and muscle sampling}

Five pigs per treatment were randomly chosen and slaughtered in a commercial slaughterhouse between d 22 and 28 , and the treatments were maintained during this period. Each pig carcass was scalded and scraped, and the eviscerated carcass was split longitudinally, with the head and feet kept on it. The right side of the carcass was dissected, and the head and feet were discarded. The longissimus muscle was separated from the loin cut. The liver and the small intestine (washed and free of mesentery) were collected. All samples were sealed in separate vacuum plastic bags and stored for a maximum of 2 months at $-20^{\circ} \mathrm{C}$ until sampling. The liver and small intestinal tissue were ground twice and sampled. The pool of dissected muscles was cut into cubes and mixed for grinding. The longissimus dorsi and a pool of all the other muscles were ground four times and sampled. All the samples were freeze-dried and stored at $-80^{\circ} \mathrm{C}$ until analysis.

\section{Chemical and biochemical analyses}

Two replicates of each sample were analyzed using the Association of Official Analytical Chemists [25] standard methods for lyophilization (method 938.18), determination of protein in the feed, liver, and small intestinal tissue (method 992.15) (Kjeltec 2400; FOSS Tecator, Hillerød, Denmark), and determination of lipids (method 991.36) (Soxtec 2050 Automated Extraction System; FOSS, Höganäs, Sweden). Crude protein (CP), collagen, and fat in the longissimus dorsi and in the pool of carcass muscles were determined by near-infrared transmittance (method 2007.04) (FOSS FoodScan near-infrared spectrophotometer), and dry matter (DM) (method 950.46) and ash (method 920.153) were also determined. Concentrations of AAs in plasma were determined as suggested by Calder et al. [26]. Thus, the pool of carcass muscles and of longissimus dorsi muscle were first lyophilized, and the samples were hydrolyzed with a solution of $\mathrm{HCl} 6 \mathrm{~mol} / \mathrm{L}$ and $0.1 \%$ phenol in a block digester at $110{ }^{\circ} \mathrm{C}$ for $24 \mathrm{~h}$. A mixture of standard isotopes $(200 \mu \mathrm{L})$ was added to the samples. A solution of $100 \mu \mathrm{l}$ of DL-dithiothreitol (15.4 $\mathrm{mg} / \mathrm{mL}$ of water) was added to the sample which for 30 min at room temperature. Afterwards, the samples were passed through columns (Poly-Prep 731-1550; Bio-Rad, Brossard, QC, Canada) prepared with $0.8 \mathrm{~cm}(0.4 \mathrm{~mL})$ of resin (Dowex 50WX8-200 ion exchange resin; Sigma-Aldrich, Oakville, ON, Canada). The columns were rinsed twice with $2 \mathrm{~mL}$ of ultra-pure water. Amino acids were recovered by adding $2 \mathrm{~mL}$ of $\mathrm{NH}_{4} \mathrm{OH}_{2} \mathrm{~N}$ to the columns. The columns were rinsed with $1 \mathrm{~mL}$ of ultra-pure water and left to drain into vials. The vials were covered with Parafilm and vortexed. The samples were frozen at $80^{\circ} \mathrm{C}$ and lyophilized. The vials were rinsed with $250 \mu \mathrm{L}$ of ultra-pure water, and the contents were transferred to a reaction vial (Pierce 13,221;). The contents of the reaction vials were dried with nitrogen at $90{ }^{\circ} \mathrm{C}$ for about $20 \mathrm{~min}$, and $20 \mu \mathrm{L}$ of DL-dithiothreitol $(15.4 \mathrm{mg} / \mathrm{mL})$ and $80 \mu \mathrm{L}$ of $\mathrm{NH}_{4} \mathrm{OH}_{2} \mathrm{~N}$ were added to the samples. The samples were left to stand for $30 \mathrm{~min}$ at room temperature and were then dried with nitrogen at $90{ }^{\circ} \mathrm{C}$ for 20 min before being derived with $60 \mu \mathrm{L}$ of MTBSTFA:DMF 1:1 (MTBSTFA: Aldrich 394,882, DMF: Aldrich 27.054-7; Oakville, ON, Canada).). The samples were heated at 90 ${ }^{\circ} \mathrm{C}$ for $35 \mathrm{~min}$ and transferred to vials for gas chromatography (Agilent 5182-0714 vials; Agilent Technologies, Saint-Laurent, QC, Canada). All AA samples were measured by gas chromatography-mass spectrometry (Agilent Technologies 7890B gas chromatograph system coupled to an Agilent Technologies 5977A mass selective detector). The immunoglobulin G (IgG) content was determined by means of enzyme-linked immunosorbent assay (ELISA) kits (Pig IgG ELISA Quantitation Set, ref. E100-104; Bethyl Laboratories, Inc., Montgomery, TX, USA). The biochemical and enzymatic analyses of plasma were performed with an automatic analyzer (Beckman DxC 600; Beckman Coulter, Mississauga, ON, Canada) by a dedicated external laboratory (Faculté de médecine vétérinaire, Université de Montréal, Saint-Hyacinthe, QC, Canada). 


\section{Calculations and statistical analysis}

Total pig weight gain was calculated as the difference between the weight measured at the beginning of the trial and the weight measured at the end of the trial. The SID Lys, SID Thr, and CP intakes were obtained for each pig by tallying the daily amount of nutrients provided by each of the blended feeds that were served. Lysine retention and Thr retention were estimated by assuming that $6.9 \%$ of body protein is Lys [27] and 3.7\% of body protein is Thr [28]. The availability of these AAs for protein synthesis was estimated by removing from the SID pool the amounts used for maintenance. Lysine and Thr maintenance requirements were estimated by adding together the basal endogenous losses, the losses related to desquamation in the digestive tract, and the losses related to the basal renewal of body proteins [29]. Lysine efficiency of utilization and Thr efficiency of utilization were calculated by dividing the corresponding retained amount by the available AA intake. The DXA body lean and fat masses were converted to their protein and lipid chemical equivalents [30]. Protein deposition in gain (\%) was calculated by dividing the PD by the ADG. Nitrogen excretion values were obtained by subtracting the respective nutrient retention and intake values.

Performance and carcass data were analyzed as a $2 \times 5$ factorial arrangement using a mixed model in SAS (version 9.4; SAS Institute Inc., Cary, NC, USA). The main effects were the feeding system, the Thr level, and their interaction, and the block was considered a random effect. The assumption of normal distribution of variables was checked using the Cramer-von Mises test within the UNIVARIATE procedure of SAS. The uncertainty in the estimate of the means of the data was expressed as the maximum standard error (MSE), and a $P$-value less than 0.05 was considered to be statistically significant, whereas a $P$-value less than 0.10 was considered a tendency. Differences between individual treatments were compared with polynomial contrasts. The optimal Thr:Lys ratio was estimated for each feeding program using the NLIN procedure of SAS.

\section{Results}

All but six of the pigs consumed feed and gained weight in accordance with the expected performance of the genetic line. Three of those six pigs had low feed intake, low ADG, and recurrent fever during the adaptation period. Three other pigs were removed from the trial, one because of a severe inflammatory foot problem and two because of respiratory problems unrelated to the trial. All those pigs were treated for their specific problem and isolated, and their data were not considered in the analysis. Thus, the performance data presented in this paper come from 10 pigs for the IPF treatments with $70 \%, 115 \%$, and $130 \%$ of the ideal Thr:Lys ratio (0.65) and the GPF treatment with $85 \%$ of that ratio, 8 pigs for the IPF treatment with $85 \%$ of that ratio, and 11 pigs for all the other treatments.

\section{Growth performance, nutrient intake, and nitrogen balance}

During the trial, ADFI, SID Lys intake, CP intake, PD in gain, LipD, final $\mathrm{BW}$, and nitrogen excretion were not affected by Thr levels or feeding system (Table 2). Average daily gain, G:F, SID Thr intake, Lys efficiency of utilization, PD, and nitrogen retention increased linearly $(P<0.05)$ and Thr efficiency of utilization decreased linearly $(P<0.05)$ with the level of dietary Thr. However, growth performance, nutrient intake and $\mathrm{N}$ balance were not affected by feeding system. No interactions between Thr level and feeding system were observed.

\section{Estimation of optimal Thr:Lys ratio}

Protein deposition, ADG, and G:F were the criterion responses used to estimate the optimal levels of dietary Thr in pigs fed in the IPF and GPF systems (Table 3). These variable responses were preferred because they are directly affected by the AA supply. Increasing the Thr:Lys ratio in the IPF pigs increased the response variables under study, which prevented identification of the optimal ratio. For the pigs raised in the GPF system, however, the breakpoint of the linear-plateau model was observed at Thr:Lys ratios of $60.2 \%, 64.9 \%$, and $68.6 \%$ for PD, ADG, and G:F, respectively, whereas the breakpoint of the quadratic-plateau model was observed at Thr:Lys ratios of $68.2 \%, 71.1 \%$, and $70.6 \%$ (Fig. 1). Thus, in relation to the optimal Thr:Lys ratios obtained with the linear-plateau models for maximum PD, the ideal ratio increased by $8 \%$ when ADG was optimized and by $15 \%$ when G:F was optimized. These increases on requirements were of $4 \%$ when the quadratic-plateau were compared to linear-plateau model in both maximal ADG and G:F. A large variation was found within treatment, and in IPF only $24 \%\left(R^{2}=0.24\right)$ and in GPF only $20 \%\left(R^{2}=0.20\right)$ of the variability in the data is explained by the AA ratio.

\section{Biochemical and enzymatic responses in plasma}

Plasma creatinine $(\mu \mathrm{mol} / \mathrm{L}), \operatorname{IgG}(\mu \mathrm{g} / \mathrm{mL})$, and creatine kinase $(\mathrm{CK})(\mathrm{U} / \mathrm{L})$ were not affected by feeding system or Thr level $(P>0.10)$ (Table 4). Plasma albumin $(\mathrm{g} / \mathrm{L})$ increased $(P<0.05)$ linearly within IPF and it was not affected in the GPF pigs. Plasma total protein $(\mathrm{g} / \mathrm{L})$ increased linearly with the increase in Thr levels $(P<0.05)$ but were not affected by feeding system. C-reactive protein $(\mathrm{CRP})(\mu \mathrm{g} / \mathrm{mL})$ increased $(P<0.05)$ in a linear manner in the IPF pigs and in a quadratic manner in the GPF pigs. Alanine aminotransferase (ALT) $(\mathrm{U} / \mathrm{L})$ increased $(P<0.05)$ linearly in the IPF pigs and showed a cubic increase in the 
Table 2 Initial and final animal body composition, growth performance, and nutrient efficiency of growing barrows ( 25 to $42 \mathrm{~kg}$ body weight) fed different levels of threonine (70\%, 85\%, 100\%, 115\%, and 130\% of the ideal threonine:lysine ratio of 0.65$)$ in an individual precision-feeding (IPF) system or a group phase-feeding (GPF) system

\begin{tabular}{|c|c|c|c|c|c|c|c|c|c|c|c|c|c|c|}
\hline \multirow[t]{2}{*}{ Parameter } & \multicolumn{5}{|l|}{ IPF } & \multicolumn{6}{|l|}{ GPF } & \multicolumn{3}{|l|}{$P$-value ${ }^{2}$} \\
\hline & 70 & 85 & 100 & 115 & 130 & 70 & 85 & 100 & 115 & 130 & $\mathrm{MSE}^{1}$ & Thr & FS & Thr $\times$ FS \\
\hline Number of observations & 10 & 8 & 11 & 10 & 10 & 11 & 10 & 11 & 11 & 11 & & & & \\
\hline \multicolumn{15}{|l|}{ Initial conditions } \\
\hline Body weight, kg & 26.0 & 26.2 & 25.6 & 25.2 & 26.0 & 26.7 & 25.7 & 25.8 & 25.7 & 26.2 & 0.8 & 0.40 & 0.49 & 0.84 \\
\hline Body protein, kg & 3.94 & 3.96 & 3.83 & 3.76 & 3.93 & 4.06 & 4.00 & 3.91 & 3.87 & 3.97 & 0.17 & 0.23 & 0.18 & 0.99 \\
\hline Body lipids, kg & 1.18 & 1.19 & 1.16 & 1.14 & 1.17 & 1.21 & 1.20 & 1.17 & 1.16 & 1.19 & 0.03 & 0.16 & 0.23 & 1.00 \\
\hline \multicolumn{15}{|c|}{ Final conditions, growth performance, and nutrient efficiency } \\
\hline Body weight, kg & 39.54 & 40.45 & 41.47 & 41.59 & 43.45 & 40.80 & 42.48 & 42.06 & 41.74 & 42.28 & 1.09 & 0.11 & 0.37 & 0.57 \\
\hline Body protein, $\mathrm{kg}$ & 6.59 & 6.68 & 6.83 & 6.94 & 7.28 & 6.86 & 6.95 & 7.04 & 6.98 & 7.12 & 0.23 & 0.16 & 0.31 & 0.76 \\
\hline Body lipids, kg & 2.76 & 2.75 & 2.71 & 2.56 & 2.61 & 2.76 & 2.89 & 2.73 & 2.61 & 2.59 & 0.23 & 0.64 & 0.72 & 0.99 \\
\hline Average daily feed intake, $\mathrm{kg} / \mathrm{d}$ & 1.44 & 1.46 & 1.46 & 1.63 & 1.50 & 1.51 & 1.40 & 1.49 & 1.48 & 1.41 & 0.14 & 0.41 & 0.35 & 0.47 \\
\hline Average daily gain, $\mathrm{kg} / \mathrm{d}$ & 0.64 & 0.67 & 0.76 & 0.80 & 0.83 & 0.68 & 0.73 & 0.78 & 0.77 & 0.76 & 0.04 & $0.01^{\dagger}$ & 0.63 & 0.17 \\
\hline $\mathrm{G}: \mathrm{F}^{3} \mathrm{~kg} / \mathrm{kg}$ & 0.46 & 0.47 & 0.51 & 0.51 & 0.56 & 0.45 & 0.49 & 0.52 & 0.52 & 0.56 & 0.04 & $<0.001^{\dagger}$ & 0.64 & 0.87 \\
\hline SID 4 lysine intake, $g / d$ & 11.5 & 12.3 & 12.2 & 13.3 & 12.9 & 13.0 & 12.0 & 12.8 & 12.7 & 12.1 & 1.3 & 0.63 & 0.86 & 0.22 \\
\hline SID threonine intake, $\mathrm{g} / \mathrm{d}$ & 6.3 & 7.9 & 8.9 & 11.0 & 11.5 & 7.1 & 7.6 & 9.3 & 10.2 & 11.4 & 0.9 & $<0.001^{\dagger}$ & 0.99 & 0.33 \\
\hline Threonine efficiency, ${ }_{1}^{5} \%$ & 84 & 68 & 65 & 56 & 54 & 75 & 68 & 65 & 57 & 55 & 0.07 & $<0.001^{\dagger}$ & 0.53 & 0.46 \\
\hline Lysine efficiency, ${ }^{6} \%$ & 80 & 78 & 87 & 85 & 93 & 73 & 78 & 88 & 88 & 94 & 0.09 & $<0.001^{\dagger}$ & 0.83 & 0.77 \\
\hline Protein deposition, $\mathrm{g} / \mathrm{d}$ & 126.2 & 129.7 & 141.4 & 151.1 & 159.5 & 130.9 & 143.1 & 149.7 & 148.5 & 150.2 & 8.3 & $<0.001^{\dagger}$ & 0.54 & 0.59 \\
\hline Protein in gain, $\%$ & 19.0 & 19.1 & 19.1 & 19.2 & 19.3 & 19.0 & 19.2 & 19.4 & 19.4 & 19.6 & 0.3 & 0.43 & 0.25 & 0.99 \\
\hline Lipid deposition, g/d & 74.8 & 74.1 & 74.7 & 68.3 & 68.4 & 74.2 & 81.0 & 74.4 & 69.0 & 66.8 & 10.1 & 0.70 & 0.84 & 0.99 \\
\hline \multicolumn{15}{|l|}{ Nitrogen balance } \\
\hline Crude protein intake, $\mathrm{g} / \mathrm{d}$ & 222.3 & 238.4 & 236.2 & 258.2 & 248.6 & 250.2 & 230.1 & 247.0 & 244.6 & 234.0 & 19.48 & 0.56 & 0.95 & 0.22 \\
\hline Efficiency of nitrogen retention, \% & 55.34 & 54.68 & 60.53 & 59.07 & 64.51 & 51.25 & 54.66 & 61.25 & 61.08 & 65.25 & 4.77 & $<0.001^{\dagger}$ & 0.94 & 0.80 \\
\hline Nitrogen excretion, g/d & 16.34 & 17.39 & 14.90 & 16.17 & 14.26 & 18.55 & 16.60 & 15.58 & 15.40 & 13.41 & 2.96 & $0.05^{\ddagger}$ & 0.91 & 0.70 \\
\hline
\end{tabular}

${ }^{1} \mathrm{MSE}$, maximum standard error

${ }^{2}$ Thr, level of threonine; FS, feeding system; $L \times$ Thr, interaction between level of threonine and feeding system; ${ }^{\dagger}$ linear effect for Thr; ${ }^{\ddagger}$ tendency for a linear effect for Thr ${ }^{3} \mathrm{G}: F$, gain:feed ratio

${ }^{4} \mathrm{SID}$, standardized ileal digestible

${ }^{5}$ Threonine $($ Thr $)$ efficiency $=\left\{(\mathrm{PD} \times 0.037)-\left[0.313 \mathrm{~g} \mathrm{Thr} / \mathrm{kg}\right.\right.$ dry matter $\left.\left.\times \mathrm{DFI}+\left(0.0033 \mathrm{~g} \mathrm{Thr} / \mathrm{kg}^{0.75} \mathrm{~d} \times \mathrm{BW}^{0.75}\right)+\left(0.0138 \mathrm{~g} \mathrm{Thr} / \mathrm{kg}^{0.75} \mathrm{~d} \times \mathrm{BW}^{0.75}\right)\right]\right\} / \mathrm{SID}$ Thr intake, where PD is protein deposition, DFI is daily feed intake, and BW is body weight

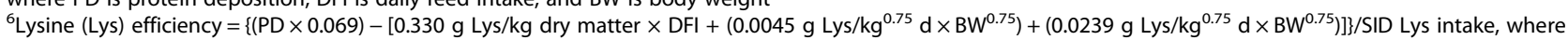
PD is protein deposition, DFI is daily feed intake, and BW is body weight

GPF pigs. Aspartate aminotransferase (AST) (U/L) tended $(P<0.10)$ to increase linearly as dietary Thr increased and tended $(P<0.10)$ to be $8 \%$ higher in the IPF pigs than in the GPF pigs. Lactic acid dehydrogenase (LDH) (U/L) tended to be $9 \%$ higher in the IPF pigs than in the GPF pigs. Urea $(\mu \mathrm{mol} / \mathrm{L})$ decreased $(P<0.05)$ in a quadratic manner in both feeding systems.

\section{Free AAs in plasma}

The dietary essential AAs (EAAs) His, Lys, and Thr (Table 5) were affected in a cubic, quadratic, and linear manner, respectively, by dietary Thr level $(P<0.05)$ but were not affected by feeding system. Methionine was not affected by dietary Thr level but was $11 \%$ higher in the
IPF pigs than in the GPF pigs $(P<0.05)$. The other EAAs were not affected by dietary $\mathrm{Thr}$ level or feeding system. The dietary non-essential AAs (NEAAs) glutamine (Glu) tended $(P<0.10)$ to increase in a quadratic manner as a function of dietary Thr level, whereas the NEAAs glycine (Gly), proline (Pro), and homocysteine tended $(P<0.10)$ to increase linearly with the increase in dietary Thr level. Serine (Ser) increased but tyrosine (Tyr) decreased linearly with the increase in dietary Thr level $(P<0.05)$. Serine was $7 \%$ higher in the IPF pigs than in the GPF pigs $(P<0.05)$. The NEAAs Glu, glutamate, Gly, homocysteine, Pro, Ser, and Tyr increased in a linear manner as dietary Thr level increased, but only Ser was affected by the feeding system, being $4 \%$ lower in the IPF pigs than in the GPF pigs. 
Table 3 Non-linear model parameters between the independent response variables (protein deposition, average daily gain, and gain:feed ratio) and the threonine:lysine ratio in an individual precision-feeding (IPF) system and a group phase-feeding (GPF) system estimated with a linear-plateau model and a quadratic-plateau model

\begin{tabular}{|c|c|c|c|c|c|c|c|c|c|}
\hline \multirow[t]{2}{*}{ Feeding system } & \multirow[t]{2}{*}{ Response $^{b}$} & \multicolumn{8}{|c|}{ Model parameter ${ }^{a}$} \\
\hline & & $U$ & SEe & R & SEe & L & SEe & $P$-value & RSE \\
\hline \multicolumn{10}{|c|}{ Linear-plateau model } \\
\hline \multirow[t]{3}{*}{ IPF } & PD & -0.873 & 0.25 & 85.4 & 6.91 & 159.5 & - & 0.00 & 24.33 \\
\hline & ADG & 0.00505 & 0.002 & 82.2 & 11.37 & 0.8295 & 0.04 & 0.00 & 0.12 \\
\hline & $\mathrm{G}: \mathrm{F}$ & - & - & - & - & - & - & - & - \\
\hline \multirow[t]{3}{*}{ GPF } & PD & -1.2239 & 0.99 & 60.2 & 9.89 & 149.5 & 3.76 & 0.07 & 21.61 \\
\hline & ADG & -0.00376 & 0.001 & 64.9 & 24.01 & 0.77 & 0.02 & 0.24 & 0.12 \\
\hline & $\mathrm{G}: \mathrm{F}$ & -0.0056 & 0.003 & 68.6 & 6.45 & 0.5362 & 0.01 & 0.03 & 0.08 \\
\hline \multicolumn{10}{|c|}{ Quadratic-plaateau model ${ }^{k}$} \\
\hline \multirow[t]{3}{*}{ GPF } & PD & -0.0347 & 0.059 & 68.2 & 19.82 & 149.5 & 4.28 & 0.07 & 21.61 \\
\hline & $\mathrm{ADG}$ & -0.00011 & 0.0003 & 71.1 & 28.51 & 0.7698 & 0.03 & 0.25 & 0.12 \\
\hline & G:F & -0.00012 & 0.0002 & 70.6 & 17.33 & 0.5387 & 0.02 & 0.03 & 0.08 \\
\hline
\end{tabular}

${ }^{a} U$, fit intercept; $S E e$, standard error of the estimation; $R$, parameter corresponding to the standardized ileal digestible threonine:lysine ratio required to reach the plateau; $L$, average response estimated by the model; RSE, residual standard error

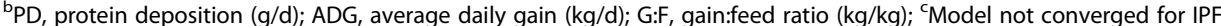

\section{Liver AAs and chemical composition}

In this growth trial (Table 6), Thr (tendency; $P<0.10$ ) and Ser $(P<0.05)$ concentrations $(\mathrm{g} \mathrm{AA} / 100 \mathrm{~g} \mathrm{CP})$ in the liver were 1 and $2 \%$ higher, respectively, in the IPF pigs than in the GPF pigs. The other EAAs and NEAAs, DM, $\mathrm{CP}$, fat, and ash were not affected by Thr level or feeding system or their interaction during the growing phase.

\section{Intestine AAs and chemical composition}

Asparagine (Asp) and Ser showed a feeding system $\times$ Thr level interaction with no effect on intestine AA composition in the IPF pigs and a cubic effect tendency $(P<0.10)$ in the GPF pigs (Table 7). Methionine tended $(P<0.10)$ to be $10 \%$ lower in the small intestinal tissue in the IPF pigs in comparison with the GPF pigs. The other EAAs and NEAAs, DM, CP, fat, and ash were not affected by Thr level or feeding system or their interaction during the growing phase. Longissimus dorsi AAs and chemical composition.
Histidine decreased linearly in the longissimus dorsi as dietary Thr level increased $(P<0.05)$, independent of feeding system (Table 8 ). Isoleucine (tendency; $P<0.10$ ) and Leu decreased $P<0.05$ linearly in the IPF pigs and in a quadratic manner in the GPF pigs. Lysine $(P<$ $0.10)$, glutamate $(P<0.10)$, Thr $(P<0.05)$, and alanine (Ala) $(P<0.05)$ increased in a quadratic manner in the IPF pigs as dietary Thr level increased, but those AA were not affected in the GPF pigs. Cysteine tended to decrease $(P<0.10)$ linearly in the IPF pigs, whereas it tended to increase linearly in the GPF pigs. Glycine tended to be $1.4 \%$ higher $(P<0.10)$ in the GPF pigs than in the IPF pigs. Collagen in the longissimus dorsi decreased $(P<0.05)$ with the increase in dietary Thr level, independent of feeding system. The other EAAs and NEAAs, DM, CP, fat, and ash were not affected by Thr level or feeding system or their interaction during the growing phase.
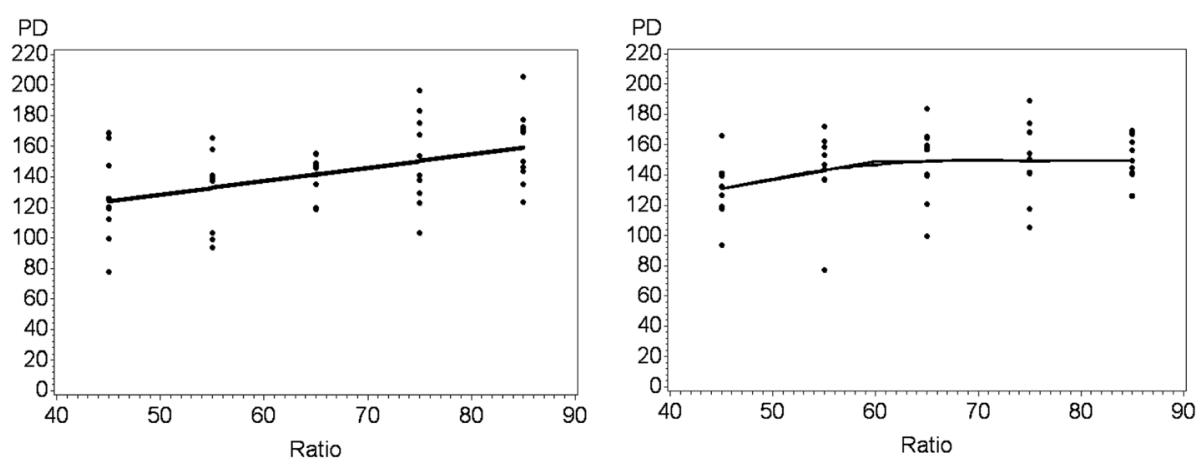

Fig. 1 Protein deposition (PD) ( $\mathrm{g} / \mathrm{d}$ ) as a function of standardized ileal digestible threonine:lysine ratio according to the linear-plateau and quadraticplateau models for pigs (25-42 kg BW) in an individual precision-feeding system (right plot) or a group phase-feeding systems (left plot) 
Table 4 Plasma free amino acid concentrations of growing barrows pigs (25 to $42 \mathrm{~kg}$ body weight) fed different levels of threonine (70\%, 85\%, 100\%, 115\%, and 130\% of the ideal threonine:lysine ratio of 0.65$)$ in an individual precision-feeding (IPF) system or a group phase-feeding (GPF) system

\begin{tabular}{|c|c|c|c|c|c|c|c|c|c|c|c|c|c|c|}
\hline \multirow[t]{2}{*}{ Parameters } & \multicolumn{5}{|l|}{ IPF } & \multicolumn{5}{|l|}{ GPF } & \multirow[b]{2}{*}{$\mathrm{MSE}^{\mathrm{a}}$} & \multicolumn{3}{|l|}{$P$-value ${ }^{b}$} \\
\hline & 70 & 85 & 100 & 115 & 130 & 70 & 85 & 100 & 115 & 130 & & Thr & FS & Thr $\times$ FS \\
\hline Number of observations & 10 & 8 & 11 & 10 & 10 & 11 & 10 & 11 & 11 & 11 & & & & \\
\hline \multicolumn{15}{|c|}{ Essential amino acids, $\mu \mathrm{mol} / \mathrm{L}$} \\
\hline Arginine & 215.26 & 210.37 & 222.60 & 212.17 & 208.10 & 216.69 & 226.5 & 217.58 & 195.36 & 210.64 & 18.40 & 0.87 & 0.98 & 0.92 \\
\hline Histidine & 54.23 & 41.64 & 39.29 & 44.31 & 30.26 & 58.55 & 45.08 & 33.79 & 35.65 & 35.50 & 4.05 & $<0.001^{e}$ & 0.92 & 0.18 \\
\hline Isoleucine & 89.37 & 78.62 & 93.25 & 82.33 & 88.10 & 84.62 & 85.85 & 82.43 & 83.39 & 83.93 & 5.35 & 0.67 & 0.43 & 0.37 \\
\hline Leucine & 148.46 & 159.01 & 169.55 & 166.34 & 155.39 & 154.52 & 153.0 & 153.95 & 156.69 & 157.46 & 7.62 & 0.27 & 0.18 & 0.25 \\
\hline Lysine & 136.93 & 80.90 & 75.53 & 59.26 & 76.68 & 125.19 & 70.60 & 64.79 & 62.92 & 64.32 & 11.86 & $<0.001^{d}$ & 0.17 & 0.89 \\
\hline Methionine & 58.56 & 51.48 & 47.48 & 48.34 & 51.24 & 46.68 & 46.42 & 44.62 & 51.22 & 40.38 & 4.71 & 0.44 & 0.04 & 0.37 \\
\hline Phenylalanine & 64.69 & 70.51 & 61.73 & 58.04 & 61.18 & 58.25 & 59.41 & 59.03 & 63.69 & 62.14 & 3.66 & 0.69 & 0.19 & 0.12 \\
\hline Threonine & 50.61 & 93.59 & 133.52 & 245.22 & 256.03 & 42.70 & 93.98 & 157.41 & 235.81 & 258.58 & 19.75 & $<0.001^{\mathrm{C}}$ & 0.87 & 0.89 \\
\hline Tryptophan & 46.20 & 41.19 & 43.72 & 39.76 & 39.57 & 44.84 & 41.96 & 40.98 & 41.36 & 42.52 & 2.76 & 0.21 & 0.87 & 0.72 \\
\hline Valine & 242.59 & 238.27 & 261.83 & 249.92 & 239.29 & 250.49 & 226.3 & 239.95 & 247.28 & 253.52 & 10.37 & 0.34 & 0.63 & 0.30 \\
\hline \multicolumn{15}{|c|}{ Non-essential amino acids, $\mu \mathrm{mol} / \mathrm{L}$} \\
\hline Alanine & 437.05 & 468.17 & 390.13 & 446.80 & 490.21 & 423.24 & 413.6 & 404.66 & 451.39 & 419.79 & 28.47 & 0.15 & 0.14 & 0.37 \\
\hline Asparagine & 39.87 & 40.07 & 42.51 & 42.70 & 41.25 & 40.86 & 40.77 & 42.00 & 40.47 & 41.52 & 3.75 & 0.94 & 0.93 & 0.98 \\
\hline Aspartic acid & 11.57 & 13.91 & 13.14 & 15.50 & 14.86 & 12.77 & 13.22 & 14.47 & 12.80 & 13.77 & 1.30 & 0.37 & 0.59 & 0.37 \\
\hline Cysteine & 193.73 & 189.57 & 204.18 & 200.91 & 211.29 & 195.79 & 200.8 & 207.32 & 195.66 & 201.82 & 7.36 & 0.17 & 0.93 & 0.54 \\
\hline Glutamate & 163.27 & 217.79 & 207.69 & 235.01 & 238.14 & 207.22 & 200.5 & 214.63 & 203.51 & 225.17 & 20.14 & 0.12 & 0.85 & 0.26 \\
\hline Glutamine & 452.58 & 483.11 & 490.92 & 491.77 & 485.81 & 438.95 & 478.8 & 500.46 & 533.40 & 477.22 & 31.74 & $0.06^{\ddagger}$ & 0.74 & 0.76 \\
\hline Glycine & 967.1 & 1116.3 & 990.8 & 1028.5 & 1108.8 & 939.9 & 914.6 & 1037.9 & 1060.6 & 1112.0 & 16.78 & $0.07^{c}$ & 0.40 & 0.18 \\
\hline Homocysteine & 19.72 & 20.42 & 22.07 & 22.29 & 25.53 & 18.15 & 20.44 & 24.24 & 22.15 & 21.70 & 2.24 & $0.08^{c}$ & 0.58 & 0.58 \\
\hline Proline & 185.7 & 194.93 & 183.91 & 206.57 & 197.87 & 186.82 & 180.70 & 188.69 & 198.42 & 187.42 & 10.56 & $0.09^{c}$ & 0.22 & 0.60 \\
\hline Serine & 93.00 & 103.71 & 99.89 & 111.67 & 108.68 & 86.12 & 93.51 & 98.25 & 98.64 & 108.81 & 4.97 & $<0.001^{\mathrm{C}}$ & 0.02 & 0.44 \\
\hline Tyrosine & 67.24 & 64.18 & 55.65 & 63.62 & 59.75 & 66.12 & 62.22 & 59.40 & 59.41 & 55.32 & 3.79 & $0.03^{c}$ & 0.45 & 0.74 \\
\hline
\end{tabular}

${ }^{\mathrm{a} M S E}$, maximum standard error

${ }^{b}$ Thr, level of threonine; FS, feeding system; $L \times T h r$, interaction between level of threonine and feeding system; ${ }^{c}$ linear effect for Thr; ${ }^{d}$ quadratic effect for Thr; e cubic effect for Thr

Pool of carcass muscle AAs and chemical composition In the pool from the right half of the carcass, the EAAs Arg, Iso, Leu, phenylalanine, Thr, and Val and the NEAAs Ser and Tyr showed an interaction between dietary Thr level and feeding system $(P<0.05)$, decreasing in a cubic manner in the IPF pigs and increasing in a cubic manner in the GPF pigs (Table 9). The EAAs His and Lys and the NEAA Asp also showed an interaction between dietary Thr level and feeding system $(P<0.05)$, with a cubic decrease in concentration in the IPF pigs and a tendency $(P<0.10)$ toward a cubic increase in the GPF pigs. The NEAAs Ala and Pro were affected by an interaction between dietary Thr level and feeding system $(P<0.05)$, with the concentration decreasing in a cubic manner in the IPF pigs and increasing in a quadratic manner in the GPF pigs. Proline $(P<0.05)$, phenylalanine and $\mathrm{Val}(P<0.05)$ and Leu $(P<0.10)$, were $5 \%, 4 \%$,
$3 \%$, respectively, higher in the GPF pigs than the IPF pigs. Threonine, Lys, Iso, Ala, Asp, Ser and Tyr were $4 \%$ $(P<0.10)$ higher in the GPF pigs than the IPF pigs. Cysteine $(P<0.05)$ and Gly $(P<0.10)$ were $6 \%$ and $4 \%$ higher, respectively, in the GPF pigs than the IPF pigs, and these AAs were not affected by dietary Thr level. Glutamate, DM, ash, fat, and collagen were not affected by Thr level or feeding system or their interaction during the growing phase. However, $\mathrm{CP}$ tended $(P<0.10)$ to be $1.5 \%$ higher in the GPF pigs than in the IPF pigs.

\section{Discussion}

Performance is affected by Thr level

Threonine levels did not affect ADFI during this growing phase, a result that is consistent with the literature $[28,31,32]$. The improved G:F ratio is due to the linear increase in ADG without changes in the ADFI. 
Table 5 Liver amino acid concentrations of growing barrows (25 to $42 \mathrm{~kg}$ body weight) fed different levels of threonine (70\%, 85\%, 100\%, $115 \%$, and $130 \%$ of the ideal threonine:lysine ratio of 0.65 ) in an individual precision-feeding (IPF) system or a group phase-feeding (GPF)

\begin{tabular}{|c|c|c|c|c|c|c|c|c|c|c|c|c|c|c|}
\hline \multirow[t]{2}{*}{ Parameter } & \multicolumn{5}{|l|}{ IPF } & \multicolumn{5}{|l|}{ GPF } & \multirow[b]{2}{*}{ MSE $^{a}$} & \multicolumn{3}{|c|}{$P$-value ${ }^{b}$} \\
\hline & 70 & 85 & 100 & 115 & 130 & 70 & 85 & 100 & 115 & 130 & & Thr & FS & Thr $\times$ FS \\
\hline Number of observations & 5 & 3 & 6 & 5 & 5 & 5 & 5 & 5 & 5 & 5 & & & & \\
\hline \multicolumn{15}{|l|}{ Chemical compositionc, \% } \\
\hline Dry matter & 28.94 & 27.70 & 28.35 & 28.73 & 28.66 & 28.08 & 28.58 & 28.29 & 28.69 & 29.04 & 0.53 & 0.59 & 0.84 & 0.49 \\
\hline Crude protein & 20.44 & 20.28 & 20.35 & 20.57 & 20.72 & 20.34 & 20.55 & 20.34 & 20.77 & 20.26 & 0.33 & 0.84 & 0.92 & 0.78 \\
\hline Fat & 7.11 & 6.21 & 6.35 & 6.17 & 6.44 & 5.91 & 6.77 & 6.69 & 6.41 & 7.43 & 0.51 & 0.72 & 0.53 & 0.19 \\
\hline Ash & 1.48 & 1.51 & 1.50 & 1.51 & 1.48 & 1.47 & 1.47 & 1.47 & 1.59 & 1.47 & 0.04 & 0.21 & 0.93 & 0.54 \\
\hline \multicolumn{15}{|c|}{ Essential amino acids, $\mathrm{g} / 100 \mathrm{~g}$ of crude protein } \\
\hline Arginine & 6.89 & 7.00 & 6.87 & 6.88 & 6.89 & 6.69 & 6.91 & 7.09 & 6.85 & 6.82 & 0.18 & 0.76 & 0.76 & 0.76 \\
\hline Histidine & 3.01 & 2.91 & 2.92 & 3.03 & 3.04 & 3.03 & 2.92 & 2.99 & 2.93 & 2.88 & 0.08 & 0.69 & 0.49 & 0.48 \\
\hline Isoleucine & 4.47 & 4.36 & 4.36 & 4.39 & 4.45 & 4.28 & 4.37 & 4.30 & 4.44 & 4.42 & 0.06 & 0.40 & 0.23 & 0.32 \\
\hline Leucine & 9.00 & 8.76 & 8.83 & 9.01 & 9.00 & 8.86 & 8.82 & 8.86 & 8.87 & 8.82 & 0.11 & 0.50 & 0.23 & 0.62 \\
\hline Lysine & 7.52 & 7.34 & 7.29 & 7.50 & 7.32 & 7.39 & 7.30 & 7.25 & 7.32 & 7.28 & 0.12 & 0.38 & 0.22 & 0.95 \\
\hline Methionine & 3.19 & 3.00 & 2.80 & 3.14 & 3.21 & 2.79 & 2.68 & 2.59 & 3.16 & 2.51 & 0.44 & 0.82 & 0.21 & 0.93 \\
\hline Phenylalanine & 5.00 & 4.87 & 4.92 & 5.03 & 5.10 & 4.97 & 4.92 & 4.99 & 4.96 & 4.93 & 0.06 & 0.24 & 0.33 & 0.14 \\
\hline Threonine & 4.48 & 4.40 & 4.38 & 4.49 & 4.44 & 4.34 & 4.38 & 4.38 & 4.41 & 4.42 & 0.05 & 0.60 & 0.09 & 0.65 \\
\hline Valine & 5.83 & 5.68 & 5.73 & 5.80 & 5.83 & 5.79 & 5.72 & 5.74 & 5.76 & 5.71 & 0.08 & 0.61 & 0.49 & 0.86 \\
\hline \multicolumn{15}{|c|}{ Non-essential amino acids, g/100 g of crude protein } \\
\hline Alanine & 5.76 & 5.64 & 5.69 & 5.73 & 5.71 & 5.71 & 5.62 & 5.68 & 5.69 & 5.61 & 0.06 & 0.39 & 0.22 & 0.94 \\
\hline Asparagine & 10.51 & 10.18 & 10.31 & 10.52 & 10.40 & 10.37 & 10.19 & 10.20 & 10.35 & 10.16 & 0.17 & 0.41 & 0.18 & 0.95 \\
\hline Cysteine & 1.14 & 1.24 & 1.33 & 1.23 & 1.19 & 1.15 & 1.18 & 1.24 & 1.23 & 1.25 & 0.06 & 0.21 & 0.65 & 0.69 \\
\hline Glutamate & 12.56 & 11.80 & 11.02 & 11.68 & 12.03 & 12.05 & 11.94 & 11.05 & 11.21 & 11.22 & 0.63 & 0.23 & 0.37 & 0.91 \\
\hline Glycine & 5.92 & 5.68 & 5.87 & 5.75 & 5.78 & 5.75 & 5.71 & 5.83 & 5.84 & 5.70 & 0.08 & 0.21 & 0.50 & 0.44 \\
\hline Proline & 4.79 & 4.64 & 4.77 & 4.76 & 4.76 & 4.67 & 4.68 & 4.73 & 4.78 & 4.66 & 0.05 & 0.24 & 0.22 & 0.40 \\
\hline Serine & 4.53 & 4.52 & 4.49 & 4.57 & 4.49 & 4.39 & 4.44 & 4.44 & 4.48 & 4.43 & 0.06 & 0.74 & 0.02 & 0.92 \\
\hline Tyrosine & 4.21 & 4.12 & 4.11 & 4.18 & 4.19 & 4.06 & 4.15 & 4.08 & 4.15 & 4.13 & 0.05 & 0.47 & 0.10 & 0.36 \\
\hline
\end{tabular}

${ }^{\mathrm{a}} \mathrm{MSE}$, maximum standard error; ${ }^{\mathrm{C}}$ Fresh basis

${ }^{\mathrm{b}} \mathrm{Thr}$, level of threonine; FS, feeding system; Thr $\times$ FS, interaction between level of threonine and feeding system

Normally, pigs fed in conventional group-feeding systems receive on average during the overall growing and finishing period $26 \%$ more Lys than pigs fed daily tailored diets do [7]. However, SID Lys intake was similar in this trial between the GPF and the IPF pigs. This similarity was due to the fact that dietary SID Lys concentration was decreased by $10 \%$ in the GPF pigs to ensure that Lys was the second-limiting AA, whereas each day, the IPF pigs received the estimated amount of SID Lys required for maintenance and growth. As well, SID Lys requirement for GPF was precisely adjusted knowing individual requirements, making this concentration (SID Lys $0.88 \%$ ), similar to the average SID Lys provided to IPF pigs (SID Lys of $0.85 \%$ ). It was this artefact that allowed us to compare both programs in equal basis avoiding Lys to drive the protein response. Still, SID Thr intake increased linearly, as expected, due to the increase in Thr concentration in the feeds.
During this growth trial, the linear increase in dietary Thr concentration allowed PD to increase linearly in both feeding systems, in line with the literature [28]. However, PD was not affected by feeding system, whereas compared with the 100\% level of SID Thr intake, 30\% Thr restriction resulted in only $12 \%$ decrease of PD. Previously, Andretta et al. [7] showed that moving from conventional to precision feeding systems does not affect growing pigs PD or performance. The percentage of protein or lipids in daily gain during the growing phase was not affected by dietary treatments even at the lower levels of PD. Cloutier et al. [7] observed a tendency of decrease in the percentage of protein in daily gain but no effect in LipD in the pigs receiving a diet $30 \%$ deficient in SID Lys. A higher backfat thickness and lower lean percentage resulted from feeding pigs with Lys deficient diets [33]. It is however expected that when dietary energy levels are sufficient to promote maximum 
Table 6 Intestine amino acid concentrations of growing barrows (25 to $42 \mathrm{~kg}$ body weight) fed different levels of threonine (70\%, 85\%, 100\%, 115\%, and 130\% of the ideal threonine:lysine ratio of 0.65$)$ in an individual precision-feeding (IPF) system or a group phase-feeding (GPF) system

\begin{tabular}{|c|c|c|c|c|c|c|c|c|c|c|c|c|c|c|}
\hline \multirow[t]{2}{*}{ Parameter } & \multicolumn{5}{|l|}{ IPF } & \multicolumn{5}{|l|}{ GPF } & \multirow[b]{2}{*}{ MSE $^{1}$} & \multicolumn{3}{|c|}{$P$-value ${ }^{2}$} \\
\hline & 70 & 85 & 100 & 115 & 130 & 70 & 85 & 100 & 115 & 130 & & Thr & FS & Thr $\times$ FS \\
\hline Number of observations & 5 & 3 & 6 & 5 & 5 & 5 & 5 & 5 & 5 & 5 & & & & \\
\hline \multicolumn{15}{|l|}{ Chemical composition ${ }^{*}, \%$} \\
\hline Dry matter & 17.14 & 16.82 & 17.26 & 17.09 & 17.44 & 17.04 & 17.39 & 17.20 & 16.76 & 17.25 & 0.33 & 0.67 & 0.90 & 0.63 \\
\hline Crude protein & 12.91 & 12.93 & 13.23 & 13.31 & 13.34 & 13.09 & 13.44 & 13.24 & 12.95 & 13.13 & 0.20 & 0.63 & 0.80 & 0.16 \\
\hline Fat & 3.04 & 2.69 & 2.78 & 2.42 & 2.69 & 2.60 & 2.62 & 2.62 & 2.54 & 2.86 & 0.24 & 0.54 & 0.57 & 0.62 \\
\hline Ash & 0.96 & 0.90 & 0.98 & 1.00 & 0.96 & 0.96 & 1.00 & 1.00 & 0.96 & 0.97 & 0.02 & 0.50 & 0.20 & 0.10 \\
\hline \multicolumn{15}{|c|}{ Essential amino acids, g/100 g of crude protein } \\
\hline Arginine & 8.17 & 8.13 & 8.01 & 8.16 & 8.02 & 7.96 & 8.29 & 8.11 & 8.00 & 8.09 & 0.10 & 0.40 & 0.94 & 0.14 \\
\hline Histidine & 2.64 & 2.60 & 2.65 & 2.63 & 2.60 & 2.57 & 2.62 & 2.66 & 2.61 & 2.65 & 0.03 & 0.51 & 0.99 & 0.42 \\
\hline Isoleucine & 4.19 & 4.13 & 4.18 & 4.14 & 4.11 & 4.04 & 4.21 & 4.20 & 4.17 & 4.17 & 0.05 & 0.47 & 0.81 & 0.10 \\
\hline Leucine & 8.13 & 8.00 & 8.18 & 8.14 & 8.12 & 7.93 & 8.22 & 8.22 & 8.14 & 8.11 & 0.08 & 0.20 & 0.84 & 0.11 \\
\hline Lysine & 7.71 & 7.55 & 7.73 & 7.63 & 7.64 & 7.47 & 7.67 & 7.74 & 7.68 & 7.71 & 0.09 & 0.37 & 1.00 & 0.21 \\
\hline Methionine & 1.80 & 1.81 & 1.57 & 1.81 & 1.57 & 2.17 & 1.88 & 2.01 & 1.85 & 1.62 & 0.21 & 0.35 & 0.09 & 0.68 \\
\hline Phenylalanine & 4.46 & 4.39 & 4.51 & 4.50 & 4.49 & 4.38 & 4.48 & 4.50 & 4.45 & 4.49 & 0.04 & 0.12 & 0.73 & 0.19 \\
\hline Threonine & 4.59 & 4.60 & 4.62 & 4.65 & 4.64 & 4.51 & 4.69 & 4.69 & 4.61 & 4.60 & 0.05 & 0.14 & 0.98 & 0.21 \\
\hline Valine & 5.19 & 5.14 & 5.21 & 5.16 & 5.16 & 5.03 & 5.23 & 5.21 & 5.18 & 5.19 & 0.06 & 0.37 & 0.88 & 0.19 \\
\hline \multicolumn{15}{|c|}{ Non-essential amino acids, g/100 g of crude protein } \\
\hline Alanine & 6.16 & 6.19 & 6.13 & 6.16 & 6.19 & 6.09 & 6.22 & 6.16 & 6.13 & 6.09 & 0.07 & 0.74 & 0.46 & 0.76 \\
\hline Asparagine & 10.92 & 10.87 & 10.97 & 11.04 & 10.83 & 10.63 & 11.00 & 10.96 & 10.72 & 10.92 & 0.11 & 0.31 & 0.21 & $0.06^{\mathrm{a}}$ \\
\hline Cysteine & 1.15 & 1.19 & 1.15 & 1.26 & 1.19 & 1.20 & 1.21 & 1.24 & 1.15 & 1.12 & 0.06 & 0.86 & 0.90 & 0.30 \\
\hline Glutamate & 14.97 & 15.19 & 14.97 & 15.22 & 14.95 & 14.89 & 15.44 & 15.20 & 15.03 & 14.90 & 0.25 & 0.46 & 0.84 & 0.83 \\
\hline Glycine & 7.96 & 8.23 & 7.79 & 8.04 & 8.08 & 8.00 & 7.99 & 7.90 & 7.90 & 7.83 & 0.19 & 0.65 & 0.38 & 0.75 \\
\hline Proline & 5.74 & 5.84 & 5.71 & 5.80 & 5.84 & 5.71 & 5.82 & 5.75 & 5.72 & 5.71 & 0.09 & 0.65 & 0.37 & 0.83 \\
\hline Serine & 4.79 & 4.78 & 4.82 & 4.85 & 4.82 & 4.74 & 4.90 & 4.90 & 4.73 & 4.79 & 0.05 & 0.26 & 0.96 & $0.08^{\mathrm{a}}$ \\
\hline Tyrosine & 4.12 & 4.08 & 4.12 & 4.12 & 4.12 & 3.99 & 4.15 & 4.15 & 4.13 & 4.12 & 0.04 & 0.33 & 0.98 & 0.15 \\
\hline
\end{tabular}

${ }^{1} \mathrm{MSE}$, maximum standard error; ${ }^{*}$ Fresh basis

${ }^{2} \mathrm{Thr}$, level of threonine; FS, feeding system; Thr $\times$ FS, interaction between level of threonine and feeding system; ${ }^{\mathrm{a}} \mathrm{cubic}$ effect within GPF

PD, but that an essential AA is limiting, PD would be reduced and the energy that is not used for protein synthesis would be stored in the form of lipids [34]. Still that growing pigs have high PD potential, but also that there is a great variation between animals. This large variation with respect to the percentage of protein in daily gain may have prevented the increase in LipD that is expected when PD is limited with a similar energy intake.

Estimated Thr and Lys efficiencies of utilization increased to nearly $100 \%$ at lower AA intake levels, with the most efficient animals in terms of AA utilization generating values over $100 \%$ of AA retention. Threonine efficiency values of 91\% [35] and 86\% [28] and Lys efficiency values of $107 \%$ and $101 \%$ [36] are found in the literature when pigs are fed AA-deficient diets. Lysine efficiency seems to increase with the level of dietary Lys deficiency, indicating that pigs are more efficient in utilizing Lys when they are fed below requirements [37]. The Lys and Thr efficiencies values found in this study are higher than those found in the literature, which are around $72 \%$ for Lys and 62\% for Thr [29]. The difference between the values observed in this trial and those in the literature may be the result of metabolic or experimental factors [38]. Thus, the increase in Lys and Thr efficiency values when pigs are fed Lys- and Thr-deficient diets may result in part from the difficulties of estimating maintenance requirements [28], which may be different from one animal to another because of each individual animal's metabolism. Furthermore, a constant efficiency value is generally proposed because body protein AA concentration is assumed to be constant and independent of the pig's age, nutrient intake, and lean and fat growth rates [28]. 
Table 7 Longissimus dorsi amino acid concentrations of growing barrows ( 25 to $42 \mathrm{~kg}$ body weight) fed different levels of threonine $(70 \%, 85 \%, 100 \%, 115 \%$, and $130 \%$ of the ideal threonine:lysine ratio of 0.65 ) in an individual precision-feeding (IPF) system or a group phase-feeding (GPF) system

\begin{tabular}{|c|c|c|c|c|c|c|c|c|c|c|c|c|c|c|}
\hline \multirow[t]{2}{*}{ Parameter } & \multicolumn{5}{|l|}{ IPF } & \multicolumn{5}{|l|}{ GPF } & \multirow[b]{2}{*}{$\mathrm{MSE}^{1}$} & \multicolumn{3}{|c|}{$P$-value ${ }^{2}$} \\
\hline & 70 & 85 & 100 & 115 & 130 & 70 & 85 & 100 & 115 & 130 & & Thr & FS & Thr $\times$ FS \\
\hline Number of observations & 5 & 3 & 6 & 5 & 5 & 5 & 5 & 5 & 5 & 5 & & & & \\
\hline \multicolumn{15}{|l|}{ Chemical composition ${ }^{*}, \%$} \\
\hline Dry matter & 24.38 & 24.49 & 24.15 & 24.05 & 24.51 & 23.95 & 23.99 & 24.55 & 24.53 & 24.30 & 0.43 & 0.96 & 0.82 & 0.47 \\
\hline Crude protein & 20.63 & 21.07 & 21.13 & 20.92 & 21.59 & 21.31 & 21.32 & 21.07 & 21.29 & 20.71 & 0.41 & 0.92 & 0.66 & $0.03^{\mathrm{a}}$ \\
\hline Fat & 2.15 & 2.05 & 1.97 & 1.44 & 1.73 & 1.70 & 1.78 & 1.71 & 1.79 & 1.95 & 0.27 & 0.66 & 0.56 & 0.30 \\
\hline Ash & 1.14 & 1.19 & 1.18 & 1.19 & 1.18 & 1.15 & 1.18 & 1.17 & 1.18 & 1.17 & 0.04 & 0.73 & 0.68 & 1.00 \\
\hline Collagen & 0.57 & 0.62 & 0.60 & 0.51 & 0.45 & 0.55 & 0.54 & 0.54 & 0.52 & 0.54 & 0.04 & $0.05^{\dagger}$ & 0.64 & $0.09^{c}$ \\
\hline \multicolumn{15}{|c|}{ Essential amino acids, g/100 g of crude protein } \\
\hline Arginine & 7.38 & 7.51 & 7.34 & 7.33 & 7.19 & 7.40 & 7.41 & 7.34 & 7.40 & 7.49 & 0.12 & 0.75 & 0.36 & 0.36 \\
\hline Histidine & 5.29 & 4.91 & 4.81 & 4.92 & 4.64 & 5.23 & 4.98 & 4.92 & 4.84 & 4.96 & 0.16 & $0.01^{\dagger}$ & 0.38 & 0.50 \\
\hline Isoleucine & 5.10 & 5.22 & 5.07 & 5.07 & 4.98 & 5.13 & 5.10 & 5.08 & 5.06 & 5.20 & 0.07 & 0.57 & 0.51 & $0.08^{\mathrm{a}, \mathrm{d}}$ \\
\hline Leucine & 8.62 & 8.68 & 8.63 & 8.57 & 8.36 & 8.68 & 8.60 & 8.56 & 8.55 & 8.74 & 0.09 & 0.60 & 0.27 & $0.02^{\mathrm{a}, \mathrm{d}}$ \\
\hline Lysine & 9.39 & 9.52 & 9.42 & 9.39 & 9.11 & 9.49 & 9.43 & 9.33 & 9.30 & 9.47 & 0.12 & 0.36 & 0.53 & $0.08^{c}$ \\
\hline Methionine & 2.66 & 2.38 & 2.70 & 2.87 & 2.52 & 2.97 & 2.45 & 2.28 & 2.41 & 2.51 & 0.23 & 0.25 & 0.40 & 0.18 \\
\hline Phenylalanine & 4.48 & 4.48 & 4.47 & 4.48 & 4.34 & 4.51 & 4.45 & 4.43 & 4.48 & 4.48 & 0.06 & 0.53 & 0.54 & 0.33 \\
\hline Threonine & 4.89 & 4.91 & 4.92 & 4.92 & 4.70 & 4.92 & 4.92 & 4.85 & 4.86 & 4.94 & 0.07 & 0.42 & 0.30 & $0.03^{c}$ \\
\hline Valine & 5.37 & 5.44 & 5.34 & 5.32 & 5.24 & 5.41 & 5.34 & 5.34 & 5.32 & 5.47 & 0.08 & 0.74 & 0.39 & 0.13 \\
\hline \multicolumn{15}{|c|}{ Non-essential amino acids, g/100 g of crude protein } \\
\hline Alanine & 6.03 & 6.10 & 6.04 & 6.05 & 5.81 & 6.12 & 6.04 & 6.03 & 6.00 & 6.08 & 0.07 & 0.14 & 0.18 & $0.02^{c}$ \\
\hline Asparagine & 11.88 & 11.76 & 11.66 & 11.85 & 11.34 & 11.81 & 11.74 & 11.80 & 11.78 & 11.85 & 0.16 & 0.35 & 0.24 & 0.14 \\
\hline Cysteine & 0.94 & 0.97 & 0.95 & 0.88 & 0.90 & 0.90 & 0.92 & 0.93 & 0.94 & 0.97 & 0.03 & 0.50 & 0.69 & $0.05^{\mathrm{a}, \mathrm{b}}$ \\
\hline Glutamate & 17.42 & 17.72 & 17.73 & 17.81 & 16.28 & 16.98 & 17.78 & 17.52 & 17.45 & 18.01 & 0.56 & 0.55 & 0.58 & $0.09^{c}$ \\
\hline Glycine & 4.75 & 4.76 & 4.70 & 4.76 & 4.57 & 4.79 & 4.73 & 4.80 & 4.75 & 4.81 & 0.07 & 0.68 & 0.08 & 0.18 \\
\hline Proline & 4.00 & 4.02 & 4.02 & 4.03 & 3.90 & 4.06 & 4.03 & 4.05 & 4.00 & 4.08 & 0.06 & 0.86 & 0.10 & 0.20 \\
\hline Serine & 4.19 & 4.13 & 4.22 & 4.21 & 4.04 & 4.23 & 4.18 & 4.16 & 4.15 & 4.17 & 0.05 & 0.13 & 0.48 & 0.16 \\
\hline Tyrosine & 4.16 & 4.19 & 4.16 & 4.18 & 4.04 & 4.20 & 4.16 & 4.14 & 4.16 & 4.19 & 0.06 & 0.65 & 0.47 & 0.32 \\
\hline
\end{tabular}

${ }^{1} \mathrm{MSE}$, maximum standard error; ${ }^{*}$ Fresh basis

${ }^{2}$ Thr, level of threonine; FS, feeding system; Thr $\times$ FS, interaction between level of threonine and feeding system; ${ }^{\dagger}$ linear effect for Thr; ${ }^{a}$ linear effect within IPF;

blinear effect within GPF; ' quadratic effect within IPF; ${ }^{d}$ quadratic effect within GPF;

Therefore, high AA efficiency of utilization might result from the fact that these efficiencies values were obtained through a back calculation using the observed PD in the pigs but assuming the Lys concentration constant as 6.9\% of the protein. This constant AA concentration in protein seems to be an invalid assumption, given that protein and energy levels [39], age [11], sulfur AA deficiency [12, 40], Thr deficiency [13] or excess, and genetics [41] can change body AA composition. The most metabolically efficient pigs may use several mechanisms, such as decreased protein degradation, increased AA absorption in the small intestinal tissue, and increased absorption of AAs from plasma proteins, to cope with lower AA intake, thereby contributing to the higher AA efficiency.

\section{Amino acid ratios cannot be used for precision feeding}

In this study, the estimated ideal Thr:Lys ratio was $65 \%$ for the GPF system, but the ideal ratio for pigs fed daily tailored diets was not clear, due the linear response to increasing Thr:Lys. Ratios based on the ideal protein profile have been assumed to be a practical way to formulate diets for non-ruminants, decreasing the use of $\mathrm{CP}[24,42$, 43]. There was concern, however, about whether these constant AA ratios could also be applied for IPF. In this feeding system, the required concentration of SID Lys is estimated individually for each pig using individual DFI and BW information. The other EAAs and the pool of NEAAs are supplied in this method using conventional ideal AA ratios. The proportional decrease in Thr as Lys 
Table 8 Carcass muscle amino acid concentrations (without longissimus dorsi) of growing barrows (25 to 42 kg body weight) fed different levels of threonine $(70 \%, 85 \%, 100 \%, 115 \%$, and 130\% of the ideal threonine:lysine ratio of 0.65$)$ in an individual precisionfeeding (IPF) system or a group phase-feeding (GPF) system

\begin{tabular}{|c|c|c|c|c|c|c|c|c|c|c|c|c|c|c|}
\hline \multirow[t]{2}{*}{ Parameter } & \multicolumn{5}{|l|}{ IPF } & \multicolumn{5}{|l|}{ GPF } & \multirow[b]{2}{*}{ MSE $^{1}$} & \multicolumn{3}{|c|}{$P$-value ${ }^{2}$} \\
\hline & 70 & 85 & 100 & 115 & 130 & 70 & 85 & 100 & 115 & 130 & & Thr & FS & Thr× FS \\
\hline Number of observations & 5 & 3 & 6 & 5 & 5 & 5 & 5 & 5 & 5 & 5 & & & & \\
\hline \multicolumn{15}{|l|}{ Chemical composition ${ }^{*} \%$} \\
\hline Dry matter & 31.10 & 30.39 & 29.84 & 29.59 & 29.94 & 29.37 & 30.22 & 30.52 & 29.84 & 29.73 & 0.76 & 0.82 & 0.55 & 0.33 \\
\hline Crude protein & 17.40 & 17.54 & 17.82 & 17.78 & 18.39 & 18.24 & 17.93 & 18.06 & 17.87 & 18.18 & 0.26 & $0.09^{\dagger}$ & 0.05 & 0.13 \\
\hline Fat & 12.84 & 12.19 & 11.46 & 10.79 & 11.25 & 10.88 & 11.67 & 10.72 & 11.05 & 11.10 & 1.02 & 0.64 & 0.23 & 0.70 \\
\hline Ash & 0.99 & 1.00 & 1.02 & 1.01 & 1.00 & 1.01 & 0.99 & 1.00 & 1.00 & 0.99 & 0.02 & 0.91 & 0.48 & 0.86 \\
\hline Collagen & 1.61 & 1.60 & 1.60 & 1.66 & 1.63 & 1.56 & 1.66 & 1.73 & 1.61 & 1.61 & 0.08 & 0.76 & 0.69 & 0.41 \\
\hline \multicolumn{15}{|c|}{ Essential amino acids, $\mathrm{g} / 100 \mathrm{~g}$ of crude protein } \\
\hline Arginine & 7.40 & 6.63 & 7.12 & 7.62 & 6.99 & 7.13 & 7.93 & 7.63 & 7.11 & 7.11 & 0.29 & 0.63 & 0.12 & $0.01^{a, b}$ \\
\hline Histidine & 4.45 & 3.68 & 3.94 & 4.30 & 4.09 & 4.27 & 4.54 & 4.28 & 3.88 & 3.99 & 0.23 & 0.48 & 0.39 & $0.02^{a, c}$ \\
\hline Isoleucine & 4.80 & 4.39 & 4.74 & 4.88 & 4.48 & 4.72 & 5.19 & 4.99 & 4.68 & 4.70 & 0.19 & 0.48 & 0.05 & $0.03^{a, b}$ \\
\hline Leucine & 8.26 & 7.57 & 8.10 & 8.46 & 7.79 & 8.12 & 9.03 & 8.22 & 8.10 & 8.10 & 0.26 & 0.61 & 0.07 & $0.01^{a, b}$ \\
\hline Lysine & 8.74 & 8.02 & 8.58 & 9.05 & 8.29 & 8.64 & 9.51 & 9.18 & 8.59 & 8.63 & 0.38 & 0.67 & 0.06 & $0.04^{a, c}$ \\
\hline Methionine & 2.56 & 2.19 & 2.28 & 2.87 & 2.73 & 2.24 & 2.87 & 2.36 & 2.66 & 2.60 & 0.26 & 0.15 & 0.87 & 0.19 \\
\hline Phenylalanine & 4.37 & 3.95 & 4.23 & 4.44 & 4.10 & 4.29 & 4.73 & 4.53 & 4.23 & 4.25 & 0.18 & 0.66 & 0.04 & $0.02^{a, b}$ \\
\hline Threonine & 4.56 & 4.20 & 4.54 & 4.76 & 4.38 & 4.57 & 5.09 & 4.56 & 4.53 & 4.51 & 0.17 & 0.61 & 0.07 & $0.01^{a, b}$ \\
\hline Valine & 5.21 & 4.73 & 5.09 & 5.30 & 4.84 & 5.12 & 5.62 & 5.39 & 5.09 & 5.06 & 0.17 & 0.44 & 0.04 & $0.03^{a, b}$ \\
\hline \multicolumn{15}{|c|}{ Non-essential amino acids, g/100 g of crude protein } \\
\hline Alanine & 6.32 & 5.74 & 6.12 & 6.44 & 5.91 & 6.22 & 6.78 & 6.61 & 6.19 & 6.06 & 0.26 & 0.43 & 0.05 & $0.04^{\mathrm{a}, \mathrm{d}}$ \\
\hline Asparagine & 11.27 & 10.15 & 10.92 & 11.30 & 10.46 & 10.98 & 12.08 & 11.58 & 10.85 & 10.81 & 0.47 & 0.54 & 0.07 & $0.03^{a, c}$ \\
\hline Cysteine & 0.95 & 0.88 & 0.93 & 0.95 & 0.87 & 0.96 & 1.04 & 1.03 & 0.91 & 0.92 & 0.05 & 0.33 & 0.04 & 0.20 \\
\hline Glutamate & 15.37 & 13.44 & 15.39 & 13.52 & 13.37 & 14.96 & 15.28 & 15.23 & 14.10 & 13.60 & 1.20 & 0.21 & 0.49 & 0.82 \\
\hline Glycine & 5.97 & 5.48 & 5.80 & 6.14 & 5.75 & 5.97 & 6.32 & 6.47 & 5.98 & 5.74 & 0.27 & 0.44 & 0.06 & 0.11 \\
\hline Proline & 4.67 & 4.29 & 4.56 & 4.82 & 4.50 & 4.66 & 5.08 & 5.01 & 4.65 & 4.56 & 0.20 & 0.55 & 0.03 & $0.04^{a, d}$ \\
\hline Serine & 4.11 & 3.74 & 4.02 & 4.21 & 3.92 & 4.03 & 4.50 & 4.31 & 4.05 & 3.97 & 0.18 & 0.61 & 0.07 & $0.03^{a, b}$ \\
\hline Tyrosine & 4.00 & 3.63 & 3.92 & 4.04 & 3.74 & 3.91 & 4.35 & 4.12 & 3.85 & 3.89 & 0.16 & 0.55 & 0.06 & $0.02^{a, b}$ \\
\hline
\end{tabular}

${ }^{1} \mathrm{MSE}$, maximum standard error; ${ }^{*}$ Fresh basis

${ }^{2} \mathrm{Thr}$, level of threonine; FS, feeding system; Thr $\times$ FS, interaction between level of threonine and feeding system; ${ }^{\dagger}$ linear effect for Thr; ${ }^{\text {a }}$ Cubic effect within IPF;

${ }^{b}$ cubic effect within GPF; c tendency for a cubic effect within GPF; ${ }^{d}$ quadratic effect within GPF

requirement decreased seemed to limit the performance of the IPF system when a Thr:Lys ratio of $65 \%$ was used. Our findings point to the conclusion that for IPF, independent estimates of Thr and possibly other AAs requirements, are required.

Establishing recommendations for AA requirements can be hampered by the differences between individuals and the availability of dietary nutrients. More important than determining an acceptable ratio between AAs is understanding the factors that are at the origin of the differences between animals. In this trial, we observed a large variation within treatments in both feeding systems. This within-treatment variation might be associated with between-animal variation, as well as with experimental and metabolic factors. In situations where the AA intake is not sufficient to support maximum growth, the growth rate is reduced and the AA composition of muscles is changed [11]. It is possible in such situations that the AA metabolism is affected and that this effect is modulated by the composition and amount of AAs supplied in the diet. In other words, the animal does not have a requirement but rather a response to $\mathrm{AA}$ intake, thereby generating variance.

Metabolism is affected by feeding system and Thr levels Normally, AST, ALT, CK, and creatinine are the recommended variables used for identifying liver and kidney damage or failure. In this study, these biochemical variables were within the expected ranges for growing pigs [44], and therefore, the plasma enzymatic changes in 
Table 9 Blood plasma biochemical parameters of growing barrows (25 to $42 \mathrm{~kg}$ body weight) fed different levels of threonine (70\%, 85\%, 100\%, 115\%, and 130\% of the ideal threonine:lysine ratio of 0.65$)$ in an individual precision-feeding (IPF) system or a group phase-feeding (GPF) system

\begin{tabular}{|c|c|c|c|c|c|c|c|c|c|c|c|c|c|c|}
\hline \multirow[t]{2}{*}{ Parameter } & \multicolumn{5}{|l|}{ IPF } & \multicolumn{5}{|l|}{ GPF } & \multirow[b]{2}{*}{ MSE $^{1}$} & \multicolumn{3}{|l|}{$P$-value ${ }^{2}$} \\
\hline & 70 & 85 & 100 & 115 & 130 & 70 & 85 & 100 & 115 & 130 & & L & FS & $L \times F S$ \\
\hline Number of observations & 10 & 8 & 11 & 10 & 10 & 11 & 10 & 11 & 11 & 11 & & & & \\
\hline Urea, $\mu \mathrm{mol} / \mathrm{L}$ & 2.70 & 1.98 & 2.38 & 2.19 & 2.77 & 2.74 & 2.04 & 2.34 & 2.07 & 2.40 & 0.23 & $<0.01^{\ddagger}$ & 0.51 & 0.83 \\
\hline Albumin, g/L & 27.80 & 26.56 & 32.12 & 31.59 & 33.51 & 29.50 & 31.44 & 32.25 & 31.63 & 31.19 & 1.25 & $<0.01^{\dagger}$ & 0.19 & 0.03 \\
\hline Creatinine, $\mu \mathrm{mol} / \mathrm{L}$ & 116.85 & 114.69 & 112.68 & 110.85 & 117.50 & 117.50 & 116.91 & 115.35 & 112.41 & 119.41 & 3.69 & 0.25 & 0.39 & 1.00 \\
\hline Lactic acid dehydrogenase, U/L & 585.34 & 581.88 & 535.13 & 532.60 & 570.35 & 524.96 & 485.73 & 537.90 & 468.60 & 557.14 & 47.66 & 0.53 & 0.06 & 0.72 \\
\hline Total protein, g/L & 62.65 & 64.26 & 65.33 & 66.90 & 67.48 & 61.86 & 65.56 & 64.37 & 66.00 & 66.13 & 1.52 & $0.01^{+}$ & 0.52 & 0.89 \\
\hline Aspartate aminotransferase, $\mathrm{U} / \mathrm{L}$ & 36.75 & 44.96 & 38.35 & 43.80 & 43.09 & 36.89 & 37.50 & 36.60 & 36.48 & 44.21 & 3.50 & $0.08^{\dagger}$ & 0.08 & 0.34 \\
\hline Alanine aminotransferase, U/L & 47.50 & 40.79 & 39.73 & 40.00 & 38.39 & 41.14 & 45.05 & 44.37 & 36.06 & 43.90 & 3.03 & 0.14 & 0.60 & $0.04^{\mathrm{a}, \mathrm{b}}$ \\
\hline Creatine kinase, U/L & 1083 & 1561 & 1227 & 1822 & 1918 & 1108 & 1244 & 1562 & 1015 & 2172 & 412 & 0.15 & 0.67 & 0.52 \\
\hline Immunoglobulin $\mathrm{G}, \mu \mathrm{g} / \mathrm{mL}$ & 11.29 & 11.28 & 9.93 & 11.90 & 10.98 & 9.71 & 10.90 & 9.48 & 11.31 & 11.36 & 1.18 & 0.19 & 0.33 & 0.84 \\
\hline C-reactive protein, $\mu \mathrm{g} / \mathrm{mL}$ & 9.25 & 13.02 & 9.98 & 18.35 & 24.78 & 13.88 & 15.81 & 18.46 & 22.82 & 12.68 & 3.56 & $0.05^{\dagger}$ & 0.26 & $0.01^{\mathrm{a}, \mathrm{c}}$ \\
\hline
\end{tabular}

${ }^{1} \mathrm{MSE}$, maximum standard error

${ }^{2} \mathrm{~L}$, level of threonine; $F S$, feeding system; $L \times F S$, interaction between level of threonine and feeding system; ${ }^{\dagger}$ linear effect for $L ;{ }^{\ddagger}$ quadratic effect for $L ;{ }^{a}$ linear effect within IPF; ${ }^{b}$ cubic effect within GPF; ' quadratic effect within GPF

AST, ALT, and CK observed in this trial are associated more likely with changes in total muscle tissue mass and metabolism than with liver damage. The AST in plasma was $8 \%$ higher in the IPF pigs than in the GPF pigs, pointing to possible muscle breakdown. With the lowest levels of Thr intake in the IPF system (i.e., 30\% below the requirement), ALT activity and urea in plasma were increased, suggesting an increase in the deamination of Ala and other AAs and in urea synthesis. Meanwhile, in the GPF system, ALT in plasma increased in a cubic manner and urea decreased in a quadratic manner with the increase in dietary Thr level. Thus, increased ALT with linear plasma urea increase within IPF at lower levels of dietary Thr can indicate that pigs restrictive treatments had lower protein synthesis or higher AA catabolism.

C-reactive protein was within normal values for healthy pigs [44]. Nonetheless, Thr in plasma increased with the increase in Thr intake, reflecting a linear increase in CRP in the IPF pigs and a quadratic increase in CRP in the GPF pigs. C-reactive protein is a major acute-phase protein in pigs exposed to health challenges [45]. But more importantly, this protein is composed mainly of Ser (9.62\%), Gly (7.48\%) and Thr (6.4\%) [46]. Because Thr and its products are important components of CRP, it is possible that more CRP was synthesized at higher levels of Thr intake and that, at lower levels of Thr intake, CRP was degraded to provide Thr, serine, and Gly for protein synthesis. It is therefore likely that the increases in plasma Ser, Gly, and Thr favoured the synthesis of CRP. The low levels of albumin in plasma observed in the pigs in the Thr-deprived dietary treatments may point to albumin synthesis reduction. The rate of albumin synthesis is reduced in cases of malnutrition, malabsorption, or maldigestion [47], what could result from Thr deficient diets. Plasma albumin accounts for $0.5 \%$ of total body proteins, as it is the major blood protein and an important protein carrier in plasma [48]. The decrease in albumin concentration in plasma could have contributed to the reduction of the supply of AAs for the natural turnover of protein in peripheral tissues [45]. In general, we observed a linear increase in plasma proteins (albumin, total protein, and CRP) with the plasmatic increase of Thr. Albumin prevents irreversible oxidative losses by capturing excess AAs and transporting them to peripheral tissues, in order to sustain local protein synthesis [49]. When the concentration of AAs in tissue cells decreases, plasma proteins are transported into tissue cells to provide AAs and ensure cellular equilibrium [50]. Therefore, when Thr deficient diets are provided to pigs, low plasma protein concentration may occurs due use of these proteins to maintain to peripheral tissues protein synthesis; still, Thr deficiency might decrease the rate of plasma protein synthesis. Both mechanisms could be used by the metabolism to increase the efficiency with which it uses the limiting $\mathrm{AA}$, as has been observed in this and other trial [52] where pigs were fed at lower levels of Thr.

Higher concentrations of plasma Lys and His were found in the pigs fed at low levels of dietary Thr in both feeding systems. When one AA is limiting in the diet (Thr in our case), some essential AAs such as Lys [13] and His [11] will increase in plasma, probably due to their low utilization for net PD [52]. The linear increase 
in the plasma concentrations of Gly and serine in both feeding systems, might be due to the Thr linear increase in plasma. Threonine in pigs is oxidized in the liver and pancreas into Gly and Ser [53]. Plasma Met and Ser levels were $11 \%$ and $7 \%$ higher, respectively, in the IPF pigs than in the GPF pigs. This difference might suggest higher oxidation of Gly in Ser in IPF system even if the rate of conversion of Gly to Ser seems limited by intestinal capacity in young pigs [54] or higher oxidation of Glu in Ser. The higher plasma Met is likely due to lower Met retention in the small intestinal tissue of the IPF pigs, which was $10 \%$ lower than in the GPF pigs.

Splanchnic tissue tends to be preserved over AA restriction Amino acid concentration and protein content in the small intestinal tissue and liver were not affected by dietary Thr levels, with the exception of Ser and a trend for Thr in the liver, which were $2 \%$ and $1 \%$ higher, respectively, in the IPF pigs than in the GPF pigs. Other studies in which animals were fed in conventional group-feeding systems with diets deficient in either Thr [13] or sulfur AAs $[11,12]$ showed low or no impact on AA concentration in the small intestinal tissue. This lack of effect of dietary AA deficiency on small intestinal tissue AA concentration can be attributed to the fact that most of the AAs retained in the proximal part of the small intestine come from the diet [55] and that absorbed dietary AAs are used first by the splanchnic tissues [12]. We can speculate that splanchnic tissues are protected from AA deficiency because of the dietary AA pathway, which reaches the liver via the portal vein after crossing the intestinal walls. Indeed, the liver and intestine are the main sites for AA metabolism in mammals. The metabolism seems to protect the integrity of these organs before other tissues, because the liver and intestine receive the absorbed AAs before others such as the skeletal tissues, thus resulting in smaller variation in AA splanchnic tissue composition. Hamard et al. [13] found higher Thr retention in the liver and colon of Thr-deficient pigs. It is plausible that the IPF pigs that received decreasing concentrations of AAs throughout the growing period developed additional metabolic mechanisms to cope with Thr deficiency, such as higher Thr retention. The lower Thr concentration and the tendency toward lower Ser concentrations found in the pool of skeletal muscles of the IPF pigs may indicate that the organism tried to retain the limiting AA for protein synthesis in the liver in order to optimize protein synthesis at the moment of AA availability. The higher levels of AST in the IPF pigs in this and another study [51] may signal skeletal muscle protein breakdown for resynthesis during AA restriction, supporting the idea that pigs use diverse mechanisms to cope with AA deficiency.

\section{Muscle AA composition is affected differently by Thr restriction and feeding systems}

In the IPF and GPF systems evaluated in this study, muscle AA concentrations were affected by Thr restriction in an opposite cubic manner. Conde-Aguilera et al. [40] found that sulfur AA restriction had little effect on carcass AA concentration when the trial duration was $10 \mathrm{~d}$, but longer periods of restriction affected muscle protein content and AA concentration [11]. In a 14-day experiment, Hamard et al. [13] found no effect on protein content and little effect on AA concentration in carcasses muscles, with the exception of Thr, which decreased in animals with a $30 \%$ Thr restriction. The 21-day length of the present trial, which is $7 \mathrm{~d}$ longer than previous studies $[13,40]$, can explain the effects of Thr restriction on muscle AA concentration and protein content observed in our study. Protein concentration in the longissimus dorsi increased linearly in the IPF pigs and was not affected in the GPF pigs. In the longissimus dorsi, protein concentration was, on average, equal between the two systems, whereas protein concentration in the pool of carcass muscles tended to be $1.5 \%$ higher in the GPF pigs than in the IPF pigs. This lower protein concentration signals that the IPF pigs were more affected by Thr restriction than the GPF pigs were. Nutrient requirements in growing pigs change rapidly over the growing period, and animals fed in conventional GPF systems may have limiting supplies of AAs at the beginning of the phase but not necessarily throughout the entire period [23]. In an in silico study, Hauschild et al. [23] demonstrated that the optimal SID Lys concentration to be served in a 28-day feeding phase underfed part of the population during half of the period but overfed another part of the population. In contrast, the requirements of pigs fed daily tailored diets are adjusted every day, and AA concentration decreases over time [6, 56]. Thus, the IPF pigs that were restricted in Thr on the first day of the trial were restricted for the entire experimental period. This might explain the high impact of AA restrictions on protein and AA concentrations in the IPF pigs in comparison with the GPF pigs.

The difference in AA concentration among different tissues, mainly among different muscles, can be due to growth hormone action; in other words, a nutritional restriction can downregulate growth hormone mRNA receptors in the liver but also upregulate them in skeletal tissues [57]. More than feed intake and energy balance, other nutrients can regulate growth hormones. In the longissimus dorsi, for example, a Thr deficiency can upregulate growth hormone [58]. Growth hormone was not measured in this trial, but it can be speculated that the effect of Thr restriction on the AA and protein concentrations observed in this trial was also mediated by hormonal changes. Collagen has been considered a 
source of NEAA reserves, and in situations where less Thr is available, proteins that are poorer in this AA, such as collagen, can be synthesized. Threonine restriction did not affect collagen synthesis in the GPF pigs in this trial, a result that is in agreement with those of previous studies $[11,13]$ in which pigs were fed in conventional group-feeding systems. The results of the present trial seem to indicate, however, that dietary Thr can affect collagen formation in pigs in an IPF system. It is possible that the IPF pigs developed several mechanisms to cope with Thr deficiency, such as collagen synthesis along with increased AA retention in the liver, as well as the use of plasma proteins as sources of AAs for peripheral tissues during AA restriction.

\section{Conclusions}

The growth performance of growing pigs in this trial was affected by the Thr supply but not by the feeding systems under study. Dietary Thr deficiency decreased plasma proteins whereas increased collagen in the Longissimus dorsi. In addition, Thr deficiency impaired empty body composition by changing AA concentration and decreasing carcass protein in the IPF pigs in comparison with the GPF pigs. The level of dietary Thr estimated using non-linear models to optimize PD was different between the feeding systems, with the pigs in the IPF system having Thr:Lys ratio requirements that were at least $30 \%$ higher than those of the pigs in the conventional GPF system. The results of this trial show that AA requirements vary between individual pigs and cannot be accurately estimated based on traditional AA:Lys ratio studies. Furthermore, the results of this trial indicate that pigs have great capacity to deal with excess and limited AA resources, by limiting PD and changing AA composition differently among body tissues. Under limiting AA conditions, pigs modulate to some extent the utilization and retention of the limiting resource in order to maintain its natural functions in a normal manner.

\footnotetext{
Abbreviations

AA: Amino Acid; AAs: Amino Acids; ADFl: Average Daily Feed Intake; ADG: Average Daily Gain; AIPF: Automatic and Intelligent Precision Feeding ${ }^{\oplus}$; Ala: Alinine; ALT: Alanine Aminotransferase; Asp: Aspargine; AST: Aspartate Aminotransferase; BW: Body Weight; CP: Crude Protein; CRP: C-Reactive Protein; DFI: Individual Daily Feed intake; DM: Dry Matter; DXA: Dual-Energy X-Ray Absorptiometry; EAA: Essential Amino Acids; FS: Feeding System; g: Grams; g/d: Grams Per Day; G:F: Gain: Feed Ratio; Gly: Glycine; GPF: Group Phase Feeding; GPF100: Group phase-feeding with 100\% of threonine; GPF115: Group phase-feeding with 115\% of threonine; GPF130: Group phase-feeding with 130\% of threonine; GPF70: Group phase-feeding with 70\% of threonine; GPF85: Group phase-feeding with 85\% of threonine; His: Histidine; IPF: Individual Precision Feeding; IPF100: Individual Precision Feeding with 100\% of Threonine; IPF115: Individual Precision Feeding with 115\% of Threonine; IPF130: Individual Precision Feeding with 130\% of Threonine; IPF70: Individual Precision Feeding with 70\% of Threonine; IPF85: Individual Precision Feeding with 85\% of Threonine; Iso: Isoleucine; kg: Kilograms; L $\times$ F: Interaction Level and Feeding System; L: Level; Leu: Leucine; LipD: Lipid Deposition; Lys: Lysine; Met: Methionine;
}

MSE: Maximum Standard Error; N: Nitrogen; NE: Net Energy; NEAA: NonEssential Amino Acids; PD: Protein Deposition; R.S.E.: Residual Standard Error; See: Standard Error of the Estimation; Ser: Serine; SID: Standardized Ileal Digestible; Thr: Threonine

\section{Acknowledgements}

The authors thank Sophie Horth, Jocelyne Renaud, and Marcel Marcoux for their technical support, to Steve Méthot for his statistical support, and to the swine complex staff for their hard work during our trials. We also thank Ines Andretta, Jean François Bernier, and Jaap van Milgen for their comments and review suggestions.

\section{Consent of publication}

All authors critically revised the manuscript for important intellectual contents and approved the final manuscript.

\section{Funding}

This project was funded by Swine Innovation Porc under the Swine Cluster 2: Driving Results through Innovation research program. Funding was also provided by Agriculture and Agri-Food Canada (AAFC) through the Agrilnnovation Program, by industry partners and provincial producer organizations, and by Aliments Breton Inc. and Ajinomoto Animal Nutrition Europe.

Financial support was also provided by the São Paulo Research Foundation (FAPESP) (grant no. 2012/03781-0; fellowship grant no. 2014/25075-6; fellowship grant no. 2016/09703-2), the Coordenação de Aperfeiçoamento de Pessoal de Nível Superior (CAPES), and the Conselho Nacional de Desenvolvimento Científico e Tecnológico (CNPq) (fellowship grant no. 132530/2013-9) for their financial support of this project.

\section{Availability of data and materials}

The datasets generated and/or analyzed during the current study belong to Her Majesty the Queen in Right of Canada, as represented by the Minister of Agriculture and Agri-Food Canada and are not publicly available. Data can be available from the authors upon reasonable request and the permission of the representative of Her Majesty the Queen in Right of Canada.

\section{Authors' contributions}

AR performed the trial and analyzed the data. AR and CP together were major contributors in writing the manuscript and interpreting the data. MPLM and LH made substantial contributions to conception and design. MPLM, LH, and EC were involved in revising the manuscript. All authors read and approved the final manuscript.

\section{Ethics approval and consent to participate}

Animals were cared for in accordance with a recommended code of practice [15] and the guidelines of the Canadian Council on Animal Care [16], and the animal trial was approved by the Ethical and Animal Welfare Committee of Agriculture and Agri-Food Canada's Sherbrooke Research and Development Centre (Sherbrooke, QC, Canada).

\section{Competing interests}

The authors declare that they have no competing interests.

\section{Author details}

${ }^{1}$ Sherbrooke Research and Development Centre, Agriculture and Agri-Food Canada, Sherbrooke, Quebec J1M 0C8, Canada. ²Département des sciences animales, Université Laval, Quebec City, Quebec G1V 0A6, Canada. ${ }^{3}$ School of Agricultural and Veterinary Studies (FCAV), Department of Animal Science, University of São Paulo State (UNESP), Jaboticabal, São Paulo 14883-108, Brazil. ${ }^{4}$ Ajinomoto Animal Nutrition Europe, Paris Cedex 17 F-75817, France.

Received: 24 September 2018 Accepted: 28 January 2019

Published online: 22 February 2019

\section{References}

1. National Research Council. Nutrient requirements of swine, 11 th rev. ed. Washington, DC, USA: The National Academies Press; 2012.

2. Hauschild L, Lovatto PA, Pomar J, Pomar C. Development of sustainable precision farming systems for swine: estimating real-time individual amino acid requirements in growing-finishing pigs. J Anim Sci. 2012;90(7):2255-63. 
3. Pomar C, Pomar J, Rivest J, Cloutier L, Letourneau-Montminy M-P, Andretta I, Hauschild L. Estimating real-time individual amino acid requirements in growing-finishing pigs: towards a new definition of nutrient requirements in growing-finishing pigs? In: Sakomura NK, Gous RM, Kyriazakis I, Hauschild $L$, editors. Nutritional modelling for pigs and poultry. Wallingford, UK: CABI Publishing; 2015. p. 157-174.

4. Pomar C, Andretta I, Hauschild L. Meeting individual nutrient requirements to improve nutrient efficiency and the sustainability of growing pig production systems. In: Wiseman J, editor. Achieving sustainable production of pig meat. Vol. 2: Animal breeding and nutrition. Sawston, Cambridge, UK: Burleigh Dodds Science Publishing; 2017. p. 287-298.

5. Pomar C, Pomar J. Sustainable precision livestock farming: a vision for the future of the Canadian swine industry. Adv Pork Prod. 2012;23:207-13.

6. Andretta I, Pomar C, Rivest J, Pomar J, Lovatto PA, Radünz NJ. The impact of feeding growing-finishing pigs with daily tailored diets using precision feeding techniques on animal performance, nutrient utilization, and body and carcass composition. J Anim Sci. 2014;92:3925-36.

7. Andretta I, Pomar C, Rivest J, Pomar J, Radünz J. Precision feeding can significantly reduce lysine intake and nitrogen excretion without compromising the performance of growing pigs. Animal. 2016;10:1137-47.

8. Cloutier L, Pomar C, Létourneau Montminy MP, Bernier JF, Pomar J. Evaluation of a method estimating real-time individual lysine requirements in two lines of growing-finishing pigs. Animal. 2015;9:561-8.

9. Zhang GH, Pomar C, Pomar J, Del Castillo JRE. L'alimentation de précision chez le porc charcutier : Estimation des niveaux dynamiques de lysine digestible nécessaires à la maximisation du gain de poids. (Article in French, abstract in English.). Journ Rech Porc. 2012:44:171-6.

10. Remus A, Pomar C, Hauschild L. Growing pigs' simulated amino acid requirements differs between actual factorial methods. In: ADSA-ASAS Midwest meeting. Des Moines, IA, USA: Journal of Animal Science; 2015.

11. Conde-Aguilera J, Barea R, Le Floc'h N, Lefaucheur L, van Milgen J. A sulfur amino acid deficiency changes the amino acid composition of body protein in piglets. Animal. 2010;4:1349-58.

12. Conde-Aguilera JA, Le Floc'h N, Le Huërou-Luron I, Mercier Y, Tesseraud S, Lefaucheur L, van Milgen J. Splanchnic tissues respond differently when piglets are offered a diet 30\% deficient in total sulfur amino acid for 10 days. Eur J Nutr. 2016;55:2209-19.

13. Hamard A, Sève B, Le Floc'h N. A moderate threonine deficiency differently affects protein metabolism in tissues of early-weaned piglets. Comp Biochem Physiol Part A: Mol Integr Physiol. 2009;152:491-7.

14. Sève B. Alimentation du porc en croissance : intégration des concepts de protéine idéale, de disponibilité digestive des acides aminés et d'énergie nette. INRA Prod Anim. 1994;7(4):275-91.

15. National Farm Animal Care Council. Recommended code of practice for the care and handling of farm animals: pigs. Ottawa, ON, Canada: AAFC Publication; 2012.

16. Canadian Council on Animal Care. CCAC guidelines on: the care and use of farm animals in research, teaching and testing. Ottawa, ON, Canada: CCAC; 2009.

17. Pomar C, Hauschild L, Zhang GH, Pomar J, Lovatto PA. Precision feeding can significantly reduce feeding cost and nutrient excretion in growing animals. In: Sauvant D, Van Milgen J, Faverdin P, Friggens N, editors. Modelling nutrient digestion and utilisation in farm animals. Wageningen, Netherlands: Wageningen Academic Publishers; 2011. p. 327-334.

18. Andretta I, Pomar C, Kipper M, Hauschild L, Rivest J. Feeding behavior of growing-finishing pigs reared under precision feeding strategies. J Anim Sci. 2016:94:3042-50

19. Sauvant D, Perez J-M, Tran G. Tables of composition and nutritional value of feed materials: pigs, poultry, cattle, sheep, goats, rabbits, horses and fish. Wageningen, Netherlands: Wageningen Academic Publishers; 2004.

20. Simongiovanni A, Corrent E, Le Floc'h N, van Milgen J. Estimation of the tryptophan requirement in piglets by meta-analysis. Animal. 2012;6:594-602

21. Barea R, Brossard L, Le Floc'h N, Primot $Y$, van Milgen J. The standardized ileal digestible isoleucine-to-lysine requirement ratio may be less than fifty percent in eleven- to twenty-three-kilogram piglets. J Anim Sci. 2009:87:4022-31.

22. Gloaguen M, Le Floc'h N, Corrent E, Primot Y, van Milgen J. Providing a diet deficient in valine but with excess leucine results in a rapid decrease in feed intake and modifies the postprandial plasma amino acid and a-keto acid concentrations in pigs. J Anim Sci. 2012;90:3135-42.

23. Hauschild L, Pomar C, Lovatto PA. Systematic comparison of the empirical and factorial methods used to estimate the nutrient requirements of growing pigs. Animal. 2010;4:714-23.
24. van Milgen J, Dourmad J-Y. Concept and application of ideal protein for pigs. J Anim Sci Biotechnol. 2015;6:15.

25. AOAC, Official Methods of the Association of Official Analytical Chemists (AOAC). Virginia USA: Association of Official Analytical Chemists. 1990, Inc

26. Calder AG, Garden KE, Anderson SE, Lobley GE. Quantitation of blood and plasma amino acids using isotope dilution electron impact gas chromatography/mass spectrometry with $\mathrm{U}^{13} \mathrm{C}$ amino acids as internal standards. Rapid Commun Mass Spectrom. 1999;13:2080-3.

27. Mahan D, Shields R. Essential and nonessential amino acid composition of pigs from birth to 145 kilograms of body weight, and comparison to other studies. J Anim Sci. 1998;76:513-21.

28. de Lange CFM, Gillis AM, Simpson GJ. Influence of threonine intake on whole-body protein deposition and threonine utilization in growing pigs fed purified diets. J Anim Sci. 2001;79:3087-95.

29. van Milgen J, Valancogne A, Dubois S, Dourmad J-Y, Sève B, Noblet J. InraPorc: a model and decision support tool for the nutrition of growing pigs. Anim Feed Sci Technol. 2008;143:387-405.

30. Pomar C, Rivest J. The effect of body position and data analysis on the estimation of body composition of pigs by dual energy X-ray absorptiometry (DEXA). In: Proceedings of the 46th Annual Conference of the Canadian Society of Animal Science, Lethbridge, AB, Canada; 1996. p. 26.

31. Edmonds MS, Baker DH. Amino acid excesses for young pigs: effects of excess methionine, tryptophan, threonine or leucine. J Anim Sci. 1987;64:1664-71.

32. Hamard A, Sève B, Le Floc'h N. Intestinal development and growth performance of early-weaned piglets fed a low-threonine diet. Animal. 2007;1:1134-42.

33. Witte DP, Ellis M, McKeith FK, Wilson ER. Effect of dietary lysine level and environmental temperature during the finishing phase on the intramuscular fat content of pork. J Anim Sci. 2000;78:1272-6.

34. Cia MC, Edwards SA, Glasgow VL, Shanks M, Fraser H. Modification of body composition by altering the dietary lysine to energy ratio during rearing and the effect on reproductive performance of gilts. Anim Sci. 1998:66:457-63.

35. Libao-Mercado A, Leeson S, Langer S, Marty BJ, de Lange CFM. Efficiency of utilizing ileal digestible lysine and threonine for whole body protein deposition in growing pigs is reduced when dietary casein is replaced by wheat shorts. J Anim Sci. 2006:84:1362-74.

36. Cloutier L, Létourneau-Montminy M-P, Bernier JF, Pomar J, Pomar C. Effect of a lysine depletion-repletion protocol on the compensatory growth of growing-finishing pigs. J Anim Sci. 2016;94:255-66.

37. Ghimire S, Pomar C, Remus A. Variation in protein content and efficiency of lysine utilisation in growing-finishing pigs. In: Skomiał J, Lapierre H, editors. Energy and protein metabolism and nutrition. Wageningen, Netherlands: Wageningen Academic Publishers; 2016. p. 351-352.

38. Möhn S, Gillis AM, Moughan PJ, de Lange CFM. Influence of dietary lysine and energy intakes on body protein deposition and lysine utilization in the growing pig. J Anim Sci. 2000;78:1510-9.

39. Bikker $\mathrm{P}$, Verstegen MWA, Bosch MW. Amino acid composition of growing pigs is affected by protein and energy intake. J Nutr. 1994;124:1961-9.

40. Conde-Aguilera JA, Lefaucheur L, Tesseraud S, Mercier Y, Le Floc'h N, van Milgen J. Skeletal muscles respond differently when piglets are offered a diet 30\% deficient in total sulfur amino acid for 10 days. Eur J Nutr. 2016;55:117-26.

41. Xue P, Schinckel AP, Adeola O, Wiseman T, Mahan DC. Total body amino acid composition of two genetic lines of barrows and gilts from twenty to one hundred twenty-five kilograms of body weight. J Anim Sci. 2016;94(Suppl 2):91-2.

42. Boisen S. Ideal dietary amino acid profiles for pigs. In: D'Mello JPF, editor. Amino acids in animal nutrition, 2nd ed. Wallingford, UK: CABI Publishing; 2003. p. 157-168.

43. Emmert $\mathrm{J}$, Baker $\mathrm{DH}$. Use of the ideal protein concept for precision formulation of amino acid levels in broiler diets. J Appl Poult Res. 1997;6:462-70.

44. Aiello SE. Serum biochemical reference ranges. In: The Merck veterinary manual. Kenilworth, NJ, USA: Merck \& Co., Inc.; 2016. p. 3173-3174.

45. Kaneko JJ. Serum proteins and the dysproteinemias. In: Kaneko JJ, Harvey, JW, Bruss ML, editors. Clinical biochemistry of domestic animals, 5th ed. San Diego, CA, USA: Academic Press; 1997. p. 117-138.

46. Oliveira EB, Gotschlich EC, Liu T. Primary structure of human C-reactive protein. J Biol Chem. 1979;254:489-502.

47. Moshage HJ, Janssen JA, Franssen JH, Hafkenscheid JC, Yap SH. Study of the molecular mechanism of decreased liver synthesis of albumin in inflammation. J Clin Investig. 1987;79:1635-41.

48. Don BR, Kaysen G. Poor nutritional status and inflammation: serum albumin: relationship to inflammation and nutrition. Semin Dial. 2004;17:432-7. 
49. De Feo P, Horber FF, Haymond MW. Meal stimulation of albumin synthesis: a significant contributor to whole body protein synthesis in humans. Am J Physiol-Endocrinol Metab. 1992;263:E794-9.

50. Reece WO, Swenson M. The composition and functions of blood. In: Reece WO, editor. Dukes' physiology of domestic animals, 12th ed. Ithaca, NY, USA: Cornell University Press; 2004. p. 26-52.

51. Remus A, Perondi D, Gobi JP, Andretta I, Hauschild L, Montminy, M-PL, et al. Pig's biochemical plasmatic variables response to methionine ingestion in a phase-feeding program or an individual daily feeding program. In: ADSA-ASAS joint annual meeting. Orlando, FL, USA: Journal of Animal Science; 2015.

52. le Floc'h N, Sève B, Henry Y. The addition of glutamic acid or protein to a threonine-deficient diet differentially affects growth performance and threonine dehydrogenase activity in fattening pigs. J Nutr. 1994;124:1987-95.

53. Le Floc'h N, Obled C, Sève B. In vivo threonine oxidation in growing pigs fed on diets with graded levels of threonine. Br J Nutr. 1996;75(6):825-37.

54. Wang W, Dai Z, Wu Z, Lin G, Jia S, Hu S, et al. Glycine is a nutritionally essential amino acid for maximal growth of milk-fed young pigs. Amino Acids. 2014;46:2037-45.

55. Le Floc'h N, Sève B. Catabolism through the threonine dehydrogenase pathway does not account for the high first-pass extraction rate of dietary threonine by the portal drained viscera in pigs. Br J Nutr. 2005;93:447-56.

56. Pomar C, Hauschild L, Zhang G-H, Pomar J, Lovatto PA. Applying precision feeding techniques in growing-finishing pig operations. Rev Bras Zootec. 2009;38:226-37.

57. Dauncey MJ, Burton KA, White P, Harrison AP, Gilmour RS, Duchamp C, Cattaneo D. Nutritional regulation of growth hormone receptor gene expression. FASEB J. 1994;8:81-8.

58. Dauncey MJ, White P, Burton KA, Katsumata M. Nutrition-hormone receptor-gene interactions: implications for development and disease. Proc Nutr Soc. 2001;60:63-72

Ready to submit your research? Choose BMC and benefit from:

- fast, convenient online submission

- thorough peer review by experienced researchers in your field

- rapid publication on acceptance

- support for research data, including large and complex data types

- gold Open Access which fosters wider collaboration and increased citations

- maximum visibility for your research: over $100 \mathrm{M}$ website views per year

At $\mathrm{BMC}$, research is always in progress.

Learn more biomedcentral.com/submissions 